\title{
PERIFERIAS TURÍSTICAS: LA ARTICULACIÓN DE UN DESTINO RURAL DE BORDE METROPOLITANO. EL CASO DEL SURESTE DE MADRID ${ }^{1}$
}

\author{
Claudia Yubero Bernabé* \\ Universidad Complutense de Madrid \\ https://orcid.org/0000-0001-5731-333X
}

María García Hernández

Universidad Complutense de Madrid

https://orcid.org/0000-0002-8469-6150

\section{RESUMEN}

El sureste de Madrid ha sido recientemente incorporado en la agenda política regional como oportunidad para el reequilibrio turístico del territorio. El objetivo de este trabajo es evaluar el papel de los 6 principales programas acometidos desde su capacidad para generar adhesión entre los agentes locales y articulación de la red de gestión pública del turismo. El resultado del análisis refleja la realidad de unas relaciones intracomarcales débiles y polarizadas por el gobierno regional, así como un sector económico diversificado (que dificulta la adhesión del sector privado a los programas). Solo algunos atisbos de cooperación en "la periferia de la periferia" emergen como efectos positivos de tales programas. Se llama la atención hacia las limitaciones en la construcción de un destino rural de base comarcal en territorios periféricos bajo influencia metropolitana.

Palabras clave: periferia turística; políticas y programas; redes sociales; adhesión, destino.

Fecha de recepción: 8 de abril de 2019

Fecha de aceptación: 24 de septiembre de 2019

* Departamento de Geografía. Universidad Complutense de Madrid. C/Profesor Aranguren, s/n 28028 MADRID (España).E-mail: claudiayubero@ucm.es, mgarciah@ucm.es

1 Este trabajo de investigación ha sido financiado por la Dirección General de Universidades e Investigación de la Comunidad de Madrid y el Fondo Social Europeo en el marco del Programa I+D: "Los Conjuntos Patrimoniales como activos turísticos de la Comunidad de Madrid: oportunidades y problemas en perspectiva territorial". Ref.: S2015/HUM3317. 


\title{
Tourism peripheries: the articulation of a metropolitan border destination. A case study in the southeast of Madrid
}

\begin{abstract}
The southeast of Madrid has recently been incorporated into the regional political agenda as an opportunity for the tourist rebalancing of the territory. The objective of this work is to evaluate the role of the 6 main programs undertaken from the point of view of their capacity to generate articulation in this destination. The result of the analysis reflects the reality of weak relationships at the intra-regional level that are polarized by the regional government, as well as a diversified economic sector (which hinders the engagement of the private sector to public programs). Only a few glimpses of cooperation in "the periphery of the periphery" emerge as positive effects of such programs. Attention is drawn to the limitations in the construction of a rural destination with a regional base in peripheral territories under metropolitan influence.
\end{abstract}

Keywords: Tourism periphery; policy and programs; social networks; engagement; destination.

\section{INTRODUCCIÓN}

Las periferias rurales de borde metropolitano son espacios del desarrollo turístico aun parcialmente explorados a escala europea frente a las periferias turísticas que se sitúan en áreas remotas (Müller y Jansson, 2007). Y, sin embargo, el 50\% de la oferta de turismo rural europea se refiere a espacios metropolitanos (Ehrlich, 2017). En la actualidad, se da un renovado interés por estas áreas al considerarse destinos potenciales capaces de reequilibrar los flujos turísticos que saturan algunos centros urbanos como así se percibe a partir de la gran cantidad de programas de desarrollo turístico que se aplican. Entre las razones que se esgrimen se encuentra la de que tienen una situación más favorable que sus homólogas en áreas remotas por la cercanía a grandes cuencas emisoras o por unas características sociodemográficas más dinámicas, por ejemplo. Estos espacios ofrecen en el entorno metropolitano un patrimonio territorial caracterizado por su "ruralidad" (Weaver, 2016) y con alto potencial para servir de base a un desarrollo sostenible (Troitiño Vinuesa y Troitiño Torralba, 2018). Además, un contexto de cambio en las prácticas del turismo rural situaría a estos espacios a la cabeza de la transición turística (Lane y Kastenholz, 2015; Salvatore, Chiodo y Fantini, 2018) y de las oportunidades del turismo de proximidad (Díaz Soria y Llurdés Coit, 2013).

En este contexto, la Comunidad de Madrid promueve en su Estrategia Turística 2016-2019 el objetivo de "Lograr una mejor distribución geográfica y temporal del turismo, es decir, limitar la estacionalidad y conseguir un reparto equilibrado de visitantes por toda la región" (Comunidad de Madrid, 2016, p. 37). Para tal fin impulsa la creación de productos y destinos que hagan frente al gran reto de articular una oferta 
atractiva y competitiva en colaboración con los principales municipios turísticos, destinos y agentes privados del sector. Se definen así varios programas que responden a este proyecto político de reequilibrar turísticamente el territorio y que se basan en la selección de los conjuntos históricos en medio rural más monumentales o en la señalización y acondicionamiento de un cinturón ciclista por la periferia metropolitana. Se suman iniciativas de otras Direcciones Generales con una clara intención de integrar y articular otros recursos locales en el mercado turístico regional como las bodegas o los yacimientos arqueológicos. De otro lado, la política europea de desarrollo rural (PEDR) también sostiene proyectos de desarrollo turístico, pero con el objetivo de diversificación de la economía rural.

Esta investigación trata de reflexionar sobre la articulación territorial del fomento del turismo desde la óptica de estas políticas con base en una periferia turística rural de interior y de borde metropolitano como la comarca de las Vegas en el sureste de la Comunidad de Madrid. Situada en la confluencia de los ríos Tajo y Tajuña, se trata de un área sin límites definidos, ya que su tratamiento y delimitación como "comarca" responde a distintos objetivos (agrarios, turísticos y de desarrollo rural principalmente). Por tanto, la configuración de un destino turístico parte de unos límites indefinidos. El resultado de la territorialización de estos instrumentos no será una trama ordenada de actuaciones ni la construcción de un destino turístico consensuado, sino más bien un espacio de geometría variable.

El objetivo de este trabajo es evaluar los principales y más recientes programas llevados a cabo al amparo de la política turística y de la política de desarrollo rural desde el punto de vista de su capacidad para generar un destino de base comarcal. ¿Cuál es la respuesta territorial ante la llegada de los instrumentos de desconcentración del turismo en el sureste de la Comunidad de Madrid? ¿Qué capacidad tiene la acción pública turística de componer un destino turístico ampliado en este espacio periférico? Para dar respuesta a estos interrogantes, se pretende reconocer i) qué grado de adhesión reciben los programas por parte de los agentes implicados, y ii) cuál es la estructura de las relaciones desplegadas para la gestión pública del turismo y cómo ésta se percibe por los actores locales. Aun asumiendo que los ámbitos de actuación de los instrumentos varían de escala, en este trabajo se lleva a cabo un análisis a escala subregional.

La investigación se estructura de la siguiente manera: en primer lugar, se aborda un apartado teórico que plantea el problema de investigación y revisa la literatura. Después se presenta el caso de estudio y la metodología empleada. El cuerpo de la exposición consiste, en primer lugar, en caracterizar este espacio rural periférico de borde metropolitano desde el punto de vista turístico. Y, en segundo lugar, se presentan los instrumentos objeto de estudio y su vocación por ampliar el territorio turístico, para después analizar la adhesión de los actores hacia tales programas y el grado de articulación generado por los mismos. Para ello se han empleado técnicas cualitativas combinadas con un análisis cuantitativo de redes sociales. Se finaliza con una discusión de los resultados a la luz de los antecedentes teóricos y se concluye considerando un nuevo escenario de gestión turística. 


\section{REVISIÓN DE LA LITERATURA}

\subsection{Las periferias turísticas y las estrategias de reequilibrio regional}

El término de "periferia", clásico en Geografía (Markusen, 2003; Potter, 2001) ha sido explorado también en su dimensión turística. Ashton y Turner (Turner y Ash, 1975) emplean por primera vez el término de "pleasure peripheries" para referirse a aquellas periferias de los lugares centrales, que estudiara Christaller, donde el turismo aparece como una de las pocas actividades viables. Sin embargo, parte de su carácter periférico se desvanece cuando estos destinos conllevan cierto éxito de llegadas (Hall, Harrison, Weaver y Wall, 2013). Por consiguiente, y bajo cierto consenso, el concepto de "periferia turística" ha pasado a distinguir aquellos destinos de éxito situados en periferias económicas mundiales (Caribe, Islas Canarias, etc.) de aquellos destinos periféricos a los destinos principales, es decir, de aquellos espacios que absorben un limitado número de visitantes en comparación con aquellos lugares que experimentan una situación de "overtourism" (exceso de turismo, en inglés). Para Weaver (2016), se trata de lugares más distantes, menos poderosos que suelen ser proveedores de "ruralidad" y oportunidades dispersas para la actividad turística. En este sentido, aparecen las áreas rurales como principales referentes de las periferias turísticas, de forma que intersecan con las características propias de estas periferias político-económicas, caracterizadas por la lejanía de los centros; la emigración; los escasos control político, tejido económico, información e innovación; así como por una fuerte intervención pública (Bock, 2016).

La condición de "periferia turística" también es compleja porque es una cuestión de escala, es decir, relativa (Müller y Jansson, 2007) y esto conlleva dos consideraciones importantes. De un lado, existen las "periferias anidadas" y las periferias en el interior de grandes regiones turísticas centrales. Las primeras son lugares que se encuentran en áreas que a otras escalas ya se consideran remotas como las islas (Weaver, 1998) o las regiones del norte europeo y las áreas polares, espacios hacia los que sin duda se dedica la mayor parte de la literatura (Halkier et al., 2019; Ioannides y Petersen, 2013; Kauppila, Saarinen, y Leinonen, 2009). Las segundas, en el otro extremo, se refieren a aquellos espacios situados en los márgenes de los destinos urbanos centrales. Este caso ha sido estudiado en mayor medida a escala urbana que a escala metropolitana (Calle Vaquero, Ferreiro Calzada, y Mendoza de Miguel, 2018; Condevaux, Géraldine y Gravari-Barbas, 2016; Mansilla y Milano, 2019; Rátz, Smith y Michalkó, 2008; Simon, 2018).

De otro lado, la cuestión escalar supone que se reproduzcan las relaciones centro/periferia también al entrar en detalle, de modo que dentro de la periferia turística se encuentren nuevas periferias en torno a los núcleos que motivan la visita turística (Carson, Carson y Hodge, 2014; Fonseca y Ramos, 2012; Fullerton y Brouder, n.d.; Yubero y García Hernández, 2016). Así ocurre a nivel comarcal, donde destaca un núcleo que genera atracción, generalmente por albergar un patrimonio en mejor estado de conservación y de mayor valor reconocido que en el entorno. La cabecera comarcal acaba absorbiendo un número de visitas importante, en ocasiones generando, a su vez, problemas de saturación puntual, mientras su entorno ve crecer las expectativas en cuanto a su propio desarrollo turístico. El término permite, por tanto, cuestionar el sistema turístico a varias escalas de análisis, 
lo que ofrece una buena base para el estudio de la expansión de la huella turística en las periferias (Hall et al., 2013).

El reto que se plantea a nivel de políticas públicas es equilibrar el exceso de presión turística en los lugares centrales y los vacíos en las periferias turísticas, haciendo de estos vacíos, espacios más atractivos y proclives a la llegada de visitantes. Las estrategias se enmarcan en el discurso de la sostenibilidad, el reequilibrio, el reparto de beneficios, el desarrollo rural, así como en el de la integración de nuevos espacios al mercado capitalista (Biddulph, 2015).

Las periferias turísticas rurales de borde metropolitano han concitado recientemente el interés de los investigadores como espacios singulares en este sentido. Según Ehrlich (2017) el 50\% de la oferta de turismo rural europea se refiere a espacios metropolitanos. Además, el $95 \%$ de los visitantes son del propio país y el $80 \%$ de los desplazamientos se realiza a menos de 3 horas por lo que los viajes cortos generan muchas oportunidades en estas áreas. También es donde se observan con mayor nitidez los cambios recientes en la demanda: orientada hacia un turismo específico en vez de al tradicional turismo rural genérico (Ehrlich, 2017; Lane y Kastenholz, 2015; Salvatore et al., 2018). Se presentan como enclaves de valioso patrimonio territorial pues albergan una variada tipología de patrimonios, natural y cultural, material e inmaterial, referentes simbólicos, recursos a proteger y piezas relevantes de la calidad y atractivo turístico de los territorios (Calle Vaquero, 2018; Troitiño Vinuesa y Troitiño Torralba, 2018). El desarrollo del turismo patrimonial en estos espacios ha llamado la atención de muchos investigadores recientemente (Vuin, Carson, Carson y Garrett, 2016).

En las áreas metropolitanas de las capitales europeas se ve la proximidad a la gran cuenca emisora como una potencialidad de desarrollo turístico de las áreas circundantes. Así, por ejemplo, en Brandemburgo (Alemania) el turismo fue la medida con más proyectos y mayor subvención de todas las propuestas por la PEDR en 2007-2013 (Zasada y Piorr, 2015), o en Lazio (Italia) donde es una de las estrategias de la Italian Inner Areas Strategy 2014-2020 (Salvatore et al., 2018). También se reconoce la capacidad que tiene el patrimonio de atraer nuevos visitantes en Madrid donde se ha subrayado el importante papel que juega la cultura en la conformación de los flujos turísticos dentro de la región, generando visitas a iglesias, castillos y pueblos históricos (García Hernández y Calle Vaquero, 2010); o en Holanda y Bélgica hasta el punto de suponer un problema de carga de las carreteras secundarias (Jaarsma y Vries, 2013), o en Lituania donde se ha estructurado la oferta en torno a antiguos palacetes o "manoirs" (Grazuleviciute-Vileniske y Vitkuviene, 2012).

Sin embargo, numerosos lugares que parecen estar caracterizados por un rango similar de condiciones y poseen una gran cantidad de atracciones culturales o de otro tipo, muestran niveles muy diferentes de desarrollo turístico. El bajo nivel de desarrollo turístico de áreas con patrimonio tiene que ver con la mala accesibilidad, el terreno accidentado o las inclemencias del tiempo, la baja densidad de población y el bajo nivel de cualificación (Müller y Jansson, 2007), con las desavenencias entre el sector público y privado (Fonseca y Ramos, 2012) o con la alta competencia que existe en áreas donde la industria o la agricultura son sectores rentables (Zasada y Piorr, 2015). 
Por último, no importa solo la lejanía o los atributos culturales o naturales inherentes, sino también la capacidad local de involucrarse política y económicamente de la población de estas áreas (Strzelecka, Boley y Woosnam, 2017). Cierto es que las características agregadas de la periferia turística, incluidas (y en parte derivadas de) la relación histórica con el núcleo, dan como resultado un equilibrio de poder en el que las regiones periféricas son relativamente poco influyentes (Hills y Lundgren, 1977; Weaver, 1988). Por lo tanto, la base de poder político y económico del núcleo es un factor determinante en el desarrollo del turismo periférico. En el debate reciente, este determinismo está fuertemente contenido por la capacidad de agenciamiento de los actores de superar estos condicionantes estructurales (Carson et al., 2014; Chaperon y Bramwell, 2013; Salvatore et al., 2018). Esta capacidad de agenciamiento tiene dos dimensiones: una instrumental, que se corresponde con las distintas formas en que los actores se apropian de los instrumentos de acción, generalmente propuestos por políticas públicas, y otra relativa a la interacción que se despliega a través de redes formales e informales de trabajo que se encastran en contextos de cooperación y competencia (Scott, Baggio y Cooper, 2008).

\subsection{La gestión pública del turismo en áreas rurales periféricas y las redes de trabajo}

El concepto de red ha recibido una atención considerable en los estudios de políticas públicas, planificación y gestión pública del turismo debido a las posibilidades que ofrece para facilitar la coordinación de los intereses públicos y privados en torno a los recursos (Beritelli, 2011; Bramwell y Lane, 2000; Dredge, 2006; Scott y Baggio, 2008; Velasco González, 2016). De hecho, la activación de un destino turístico se interpreta como un proceso lento e informal de desarrollo de una red de gestión del turismo (Barbini y Presutti, 2014). En cuanto elemento constitutivo de los destinos, es también considerada un mecanismo de gobernanza diferenciador, propicio para la cooperación y la competitividad (Beritelli, 2011; Bramwell y Lane, 2000; Jamal y Getz, 1995; Michael Hall, 2011).

Para el estudio de las redes del desarrollo turístico se ha recurrido al análisis de redes sociales $\mathrm{y}$, aunque se trata de una técnica de mediados del siglo $\mathrm{XX}$, se viene utilizando en turismo desde los 90 con un importante crecimiento en los 2000 (Van der Zee y Vanneste, 2015). Se trata de un método de la sociología estructural donde se observa un sistema de interdependencias en un momento dado y de un grupo social determinado (Mercklè, 2011). Estas interdependencias o "relaciones sociales" tienen dos funciones esenciales en el marco de las redes: canalizan el intercambio o transferencia de recursos, materiales e inmateriales, así como reflejan un compromiso intencional entre sus miembros (Lazega, 2007). En el marco de una cuarentena de trabajos publicados, Merinero (2015) subraya la preeminencia de estudios que describen cuantitativamente las métricas de las redes, de manera que se observa un vacío en torno a los trabajos explicativos acerca de la incidencia de la red en la actividad turística. Para este cometido varios autores alientan la complementariedad de esta técnica con otras de tipo cualitativo (Baggio, Scott, y Cooper, 2010; Dredge, 2006; Merinero Rodríguez, 2015).

Las periferias turísticas rurales han sido objeto de estudio bajo este método en contadas ocasiones, tanto desde el punto de vista del desarrollo turístico (Carson et al., 2014; Nogueira y Pinho, 2015; Romeiro y Costa, 2010; Scott y Baggio, 2008; Yubero y Cheva- 
lier, 2018), como del desarrollo rural en general (Buciega Arévalo y Esparcia Pérez, 2018; Chevalier, 2014; Lacquement y Raynal, 2013). En estos contextos se subraya el papel que juegan las proximidades familiares (clanes), las asociadas a valores comunes y las organizativas (como la pertenencia al mismo partido político) para facilitar la existencia de relaciones sociales positivas. En cambio, el funcionamiento de la red se ve dificultado por un peso excesivo del sector público o el individualismo.

\subsection{Las periferias turísticas en la estructura y funcionamiento de la Comunidad de Madrid}

La región turística de Madrid se configura como un área central, que, al igual que ocurre en otras regiones capitales europeas, supera los propios límites político-administrativos de la propia Comunidad Autónoma. Según datos de FRONTUR, la Comunidad de Madrid recibió en 2017 16,56 millones de turistas (sin contabilizar excursionistas), lo que la convierte en la $6^{\mathrm{a}}$ comunidad autónoma con mayor número de turistas. De ellos, 6,14 millones de desplazamientos corresponden a los realizados por residentes en el extranjero y 9,86 millones a los realizados por turistas residentes en España, de los cuales hasta 3,16 residían en la propia Comunidad de Madrid. No obstante, estas cifras están desigualmente repartidas por el territorio de forma que las áreas menos visitadas, que conforman las periferias turísticas, se corresponden con los espacios de borde metropolitano en los tres vértices de la región.

Según la aplicación que realizan Calle Vaquero et al. (2015) del modelo de Hall para la estructura y funcionamiento de regiones turísticas metropolitanas, la Comarca de las Vegas es una de estas periferias turísticas, situada a caballo entre la tercera y cuarta zona. Alejada del nodo principal que es la propia ciudad de Madrid (primera zona) y de su anillo metropolitano (segunda zona), la tercera zona corresponde a una amplia zona periurbana de excursionismo donde predominan las visitas a conjuntos monumentales y espacios naturales protegidos y la cuarta a un amplio espacio periférico de extensos lotes de vivienda secundaria construidos a golpes de expansión inmobiliaria. Es en este espacio de periferia turística, en los intersticios de una gran región turística, donde se plantean los proyectos de reequilibrio territorial del turismo que promueve la Comunidad de Madrid.

El estudio del desarrollo turístico de los espacios periféricos de la región turística de Madrid tiene una larga trayectoria en torno a los nodos secundarios de atracción, como son las ciudades inscritas en la lista de Patrimonio Mundial de la UNESCO y Reales Sitios (Calle Vaquero et al., 2018; Mínguez García, 2007; Troitiño Vinuesa, García Hernández, y Calle Vaquero, 2011) y en torno al área metropolitana y las nuevas centralidades de ocio que conforman los centros comerciales y parques temáticos (Barrado Timón, 1999b; Bote Gómez, 1995; del Canto Fresno, 1994; Escudero, 2006). En cuanto a la periferia rural de borde metropolitano, los trabajos se han centrado en la Sierra y, concretamente, en sus microdestinos de excursionismo asociados a espacios naturales protegidos (Barrado Timón, 1999a; Martín Hernanz y Martín Gil, 2017) o a bienes de interés cultural (Martín Gil y Martín Hernanz, 2008). Las estrategias de desconcentración de los flujos turísticos hacia estos espacios no es un tema recurrente, aunque sí se ha tratado a nivel urbano en las ciudades Patrimonio Mundial (Troitiño Torralba, 2011) y en el entorno de Patones con 
serias limitaciones a la hora de prosperar (Martín Hernanz y Martín Gil, 2017). Ante esta orientación de los trabajos, es de lamentar que se hayan dejado de lado espacios ya reseñados periféricos y de perfil turístico como el sureste de la Comunidad de Madrid gracias a la atracción que generan sus pequeños conjuntos históricos (Solís, Ureña, y Mohíno, 2018).

\section{PRESENTACIÓN DEL CASO DE ESTUDIO}

La Comarca de Las Vegas se sitúa al sureste de la Comunidad de Madrid. Se trata de un territorio de perímetros variables en función del espacio reconocido (ver Figura 1), ya sea como turístico (23 municipios), agrícola (21 municipios) o para la recepción de los fondos europeos del desarrollo rural (LEADER). Tomando como referencia la comarca turística, el espacio está compuesto por 23 municipios con 154.783 habitantes en 2017 y una superficie de $1.378,13 \mathrm{~km}^{2}$, lo que supone una densidad media de 113,3 hab./ $\mathrm{km}^{2}$. Supone el 4,6\% de la población total de la Comunidad y el 18,4\% de su territorio (descontando en ambos casos el municipio de Madrid). Con respecto a 2006, el área ha aumentado un $14,5 \%$ su población y tiene un crecimiento relativo anual positivo de 0,4 . Sin embargo, esta tendencia se concentra en la mitad de los municipios más occidentales teniendo la otra mitad crecimientos negativos.

El espacio receptor de fondos LEADER es sin duda el más variable: arrancó con base en la comarca agraria, incluyendo además dos municipios al norte (Valdilecha y Villar del Olmo), pero a partir de 2007 dio comienzo un proceso de pérdida de extensión territorial ya que se dejaron de cumplir los criterios impuestos por la UE con el aumento de la densidad de los municipios donde se dio una fuerte presión urbanística: fue el caso de Ciempozuelos y Aranjuez en el periodo 2007-2013 y San Martín de la Vega y Morata de Tajuña en 2014-2020. Si bien, en este último periodo, el GAL se amplía hacia el este de la región, con el apoyo de la Comunidad de Madrid, anexionando una comarca diferente que corresponde a la zona de páramo y que se regía en el periodo anterior por el ya extinto GAL ADECHE (Asociación de Desarrollo Campiña del Henares).

Las vegas de los ríos Tajo, Tajuña y Jarama han conformado históricamente este territorio como un espacio agrario que sirvió a la ciudad de Madrid hasta mediados del siglo $\mathrm{XX}$, pero la débil vertebración actual de estos ríos, así como la disposición de los grandes ejes de infraestructuras radiales y orbitales conforman hoy un territorio de dinámica dual (Abad Aragón, 2014).

El sector occidental, formado por los municipios de Aranjuez, San Martín de la Vega y Ciempozuelos, cumple funciones metropolitanas y alberga una creciente parte de la población total de la comarca, pasando de comprender el 58\% en 1991 al 65\% en 2017. Además, son los tres municipios con mayor densidad de población (308, 478 y 178 hab. $/ \mathrm{km}^{2}$ respectivamente). El resto de los municipios se engloban en el sector oriental, espacio de expansión periurbana desigualmente conectado con el centro de la región: los municipios del valle del Tajuña-Jarama al norte están mejor conectados, mientras que, hacia el sur, los municipios del valle del Tajo tienen peor conexión física. El perfil socioeconómico de ambos sectores se diferencia igualmente. Según datos de la Tesorería General de la Seguridad Social el porcentaje de afiliados en 2017 a la rama de agricultura y ganadería en los municipios de Aranjuez, Ciempozuelos y San Martín es menor 
a la media $(1,2 \%$ frente a $2,9 \%)$ y es superior el de los afiliados a los servicios tanto los relativos al consumo y la hostelería $(39,7 \%$ frente a $36,9 \%)$ como a las empresas y financieros $(38,5 \%$ frente a $37,6 \%)$. Con el paso del tiempo, pues, esta dinámica dual (demográfica, socioeconómica y funcional) ha desdibujado la cohesión de este territorio, marcado por la presencia histórica de la agricultura de vega. No obstante, la Comarca de las Vegas aún se presenta en su conjunto como un paisaje de fuerte impronta rural y agroindustrial a partir de olivares, viñedos, campos cerealísticos y regadíos en los fondos de los valles Tajo, Jarama y Tajuña.

\section{Figura 1 \\ LOCALIZACIÓN DE LA COMARCA DE LAS VEGAS Y SUS DISTINTOS LÍMITES}

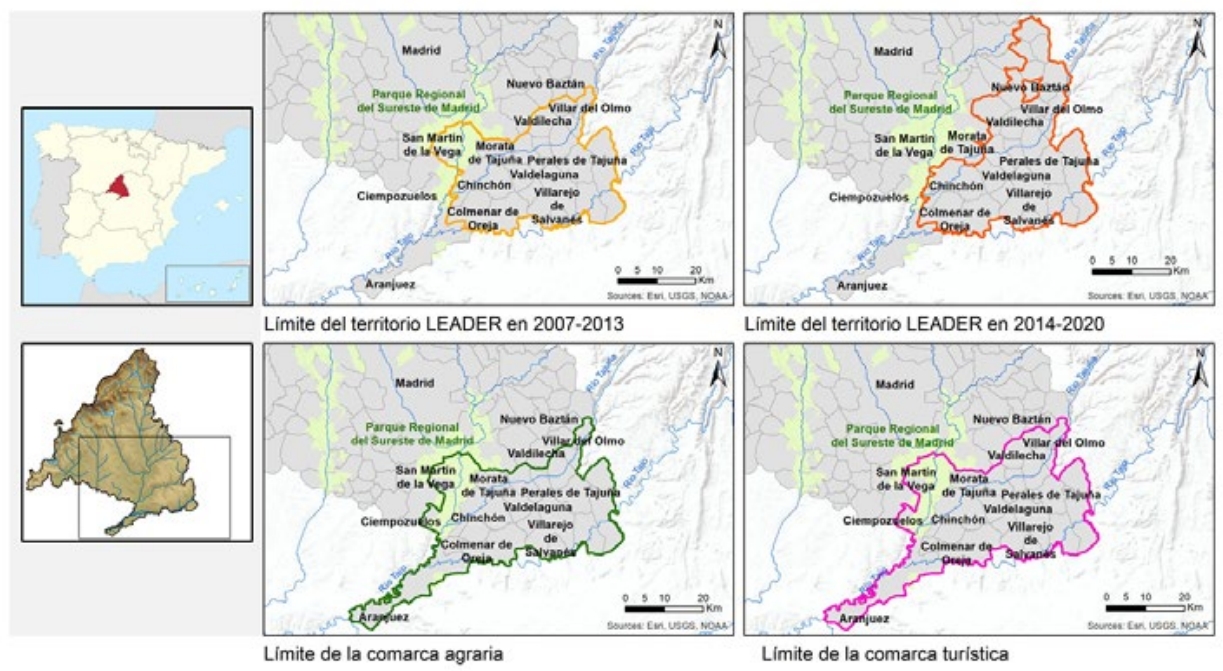

Fuente: Elaboración propia.

En términos turísticos este paisaje rural ha permitido la articulación de tímidas iniciativas de activación turística relacionadas con la gastronomía, el deporte y el enoturismo. Sin embargo, es el patrimonio histórico más monumental el que concita en buena medida la atención de los flujos de visitantes que recibe actualmente la comarca. El Real Sitio de Aranjuez es el núcleo más turístico (por la naturaleza de su propio patrimonio y por la magnitud de su demanda de visita). Se trata de una ciudad patrimonial que alberga un recinto palaciego, jardines, una villa histórica y un amplio territorio de paseos arbolados y huertas. Muchos de sus elementos están protegidos como BIC y en 2003 parte del municipio se incluyó en la Lista del Patrimonio Mundial con la categoría de Paisaje Cultural (ver Figura 2). Se trata de un destino que entra en competencia directa con otras ciudades patrimoniales de rango similar como Alcalá de Henares y San Lorenzo de El Escorial (Patrimonio Mundial). 


\section{Figura 2 \\ PANORÁMICA DEL CENTRO HISTÓRICO DE ARANJUEZ INTEGRADO EN LA FIGURA DE PAISAJE CULTURAL}

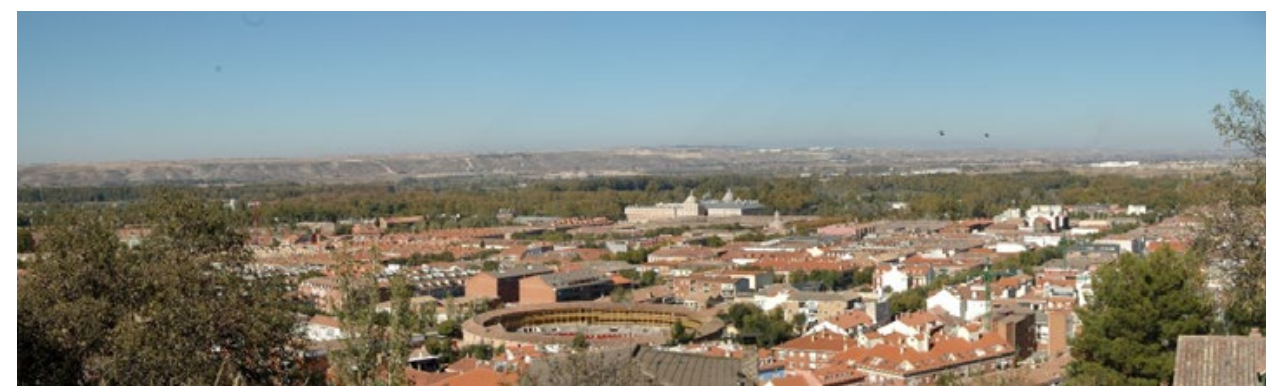

Fuente: Carmen Mínguez García.

En un nivel de importancia patrimonial, y sobre todo turística secundaria frente a los sitios incluidos en la Lista del Patrimonio Mundial, se encuentra Chinchón, como núcleo de tradicional desarrollo turístico (ver Figura 3), así como otros núcleos de reciente incorporación a la oferta turística de Madrid como Colmenar de Oreja (ver Figura 4), Villarejo de Salvanés o Nuevo Baztán (todos ellos con conjuntos históricos protegidos). Las iniciativas empresariales también han contribuido al impulso del turismo en la Comarca de las Vegas, principalmente en el sector de la hostelería, el alojamiento y, recientemente, de las bodegas vitivinícolas. En este sentido, la Denominación de Origen Vinos de Madrid (1992) ha supuesto un revulsivo para la valorización del enoturismo en la comarca conocida por mantener la producción de tinajas de barro, lo que ha dado lugar a la apertura de bodegas al público, principalmente en Colmenar de Oreja o Valdelaguna (ver Figura 5).

\section{Figura 3}

\section{VISTA DE CHINCHÓN}

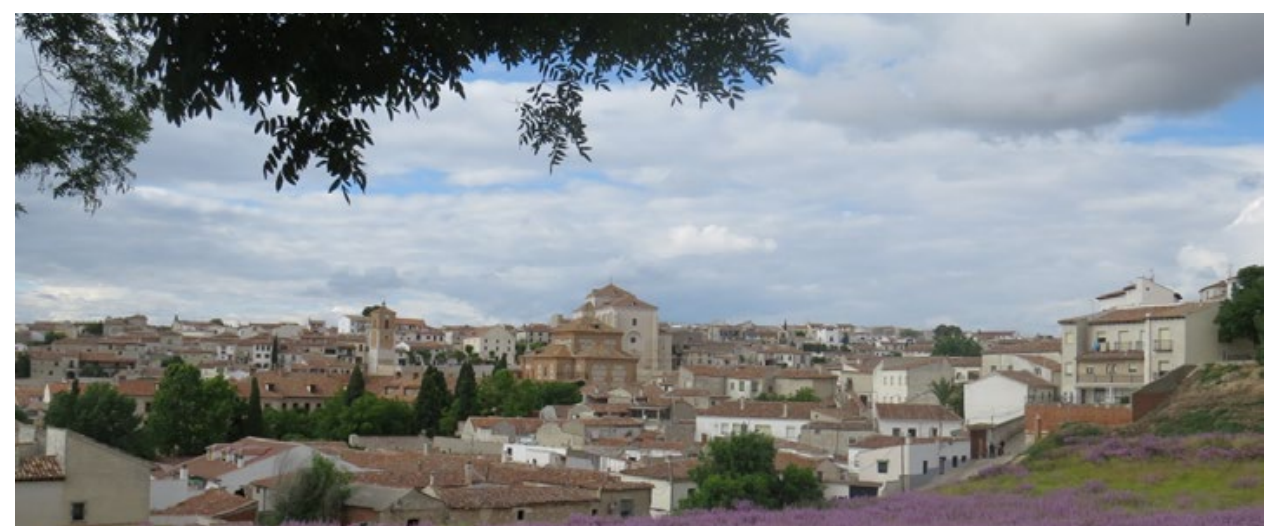

Fuente: Elaboración propia. 


\section{Figura 4 \\ PLAZA MAYOR DE COLMENAR DE OREJA}

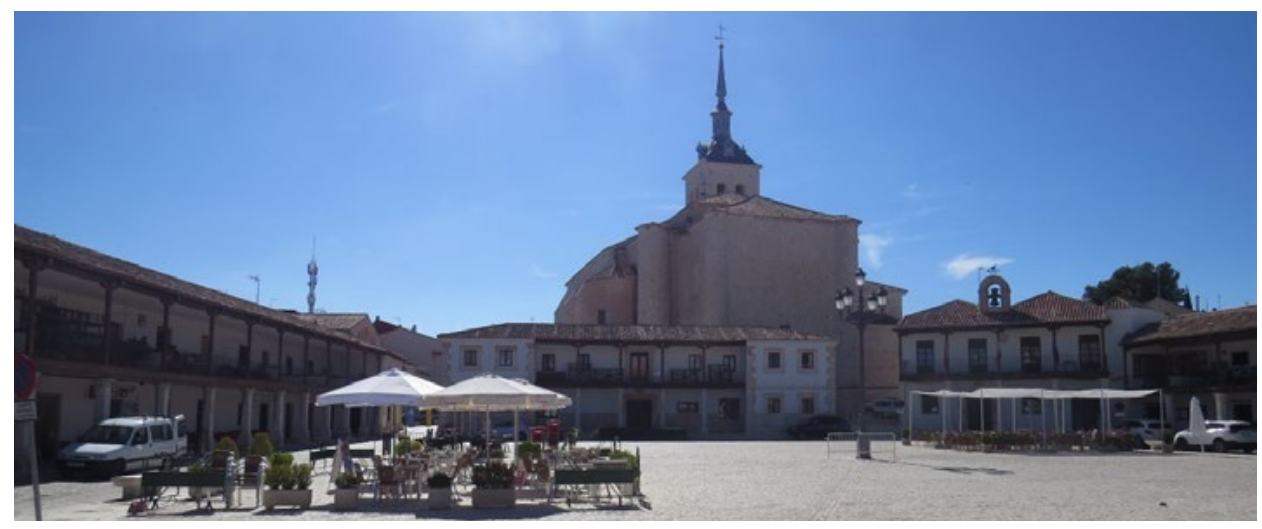

Fuente: Elaboración propia.

\section{Figura 5 \\ TINAJA DE DECORACIÓN EN UNA DE LAS CALLES PRINCIPALES DE VALDELAGUNA}

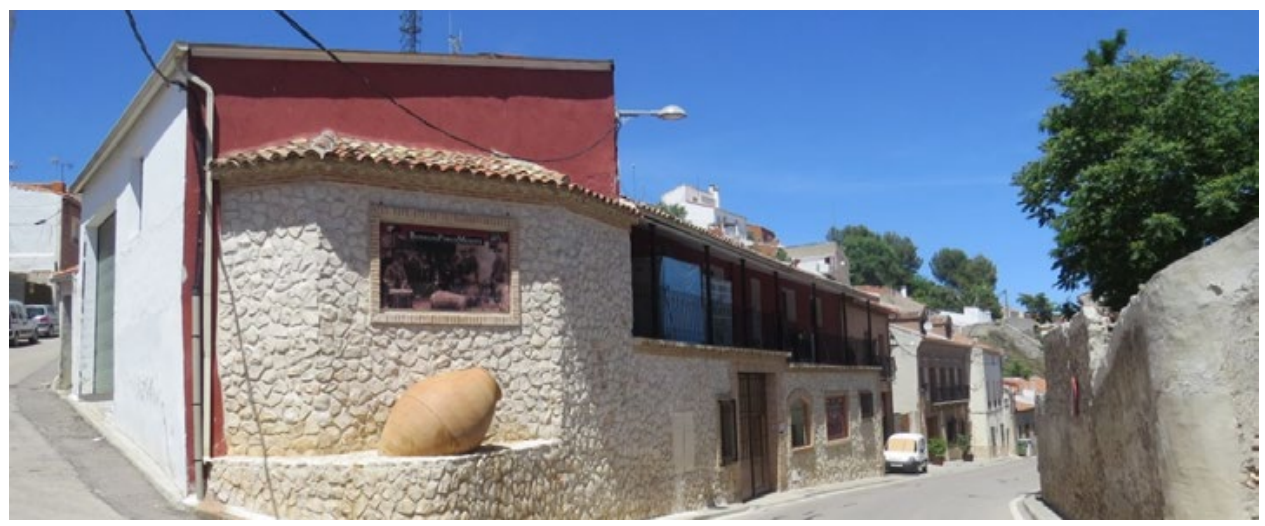

Fuente: Elaboración propia.

Junto con el patrimonio cultural, en esta comarca es posible identificar también algunos elementos de patrimonio natural con incipiente proyección de ocio turístico-recreativo como el Parque Regional del Sureste, declarado en 1994 (aunque solo una porción se despliega al noroeste de la comarca); la Reserva Natural del Regajal-Mar de Ontígola en Aranjuez y el Refugio de fauna de la Laguna de San Juan en Chinchón. Además de las visitas a estos enclaves naturales, también se ha creado la Vía Verde del Tajuña que discurre por el antiguo trazado del ferrocarril de Arganda, atravesando el valle y bosque de ribera del río Tajuña, así como las paredes de yeso (entre Perales y Tielmes) y que sirve de vía para senderistas y ciclistas. 


\section{METODOLOGÍA}

El desarrollo de esta investigación se sustenta en la utilización de diversas fuentes de información. Se han explotado las fuentes estadísticas oficiales del Instituto de Estadística de la Comunidad de Madrid, cuyos datos han sido contrastados con el Registro de alojamientos turísticos y restaurantes de la Comunidad de Madrid para el año 2016 y actualizadas con las webs Booking y Airbnb. También se ha tratado la información de las consultas en las Oficinas de Información Turística presentes en la comarca. Asimismo, se han consultado documentos de planificación turística y de planificación del desarrollo rural, así como las bases de datos de proyectos financiados por LEADER (desde 1996 hasta 2018). Y, por último, se ha realizado trabajo de campo con 22 entrevistas semiestructuradas realizadas durante los veranos de 2017 y 2018 y a principios del año 2019 a la Dirección General de Turismo de la Comunidad de Madrid (1), a agentes públicos de la comarca (10), al gerente del Grupo de Acción Local (1), a miembros o exmiembros de las juntas directivas de asociaciones empresariales (6) y al sector privado no asociado (4). El contenido de las entrevistas semiestructuradas se desarrolló en torno a 4 apartados: i) percepción de la dinámica turística de su municipio y de la comarca, ii) iniciativas turísticas más relevantes puestas en marcha, iii) valoración de éstas y iv) relación con el resto de los agentes turísticos locales, comarcales y regionales.

La metodología de análisis de esta información ha sido cuantitativa y cualitativa. En primer lugar, se ha recurrido a técnicas cuantitativas básicas de descripción estadística para caracterizar los principales rasgos del perfil turístico del área. En segundo lugar, se ha creado una base de datos discursiva para interpretar el grado de adhesión de los agentes entrevistados a los principales instrumentos analizados. Finalmente, se ha utilizado la técnica del análisis de redes sociales como aproximación al sistema de acción pública del turismo en la comarca.

El análisis de redes consiste en dibujar las relaciones (vínculos) entre los stakeholders (nodos) y deducir sus características a partir de una serie de indicadores propios de la red, como la densidad, y de cada uno de sus nodos, como los indicadores de centralidad. Aquí se utiliza el in-degree que se define como la importancia que adquiere un nodo a partir del número de relaciones que absorbe (Lazega, 2007). Este método tiene la ventaja de inferir los límites de los destinos turísticos a partir de las relaciones entre sus actores, dejando así anteriores "apriorismos" que tenían que ver con las delimitaciones político-administrativas (Bouba-Olga, Carrincazeaux, y Coris, 2008; Carson et al., 2014; Scott, 2004). Cabe destacar que los análisis de redes sociales suelen incluir también a las empresas para conocer las relaciones público-privadas. Sin embargo, se ha optado por no incluirlas aquí (pero sí en las entrevistas) para despejar la red de gestión pública del turismo. Al incluirse las asociaciones empresariales, que son los mecanismos utilizados por las empresas para influir en la toma de decisiones, se cubren las relaciones con el sector privado dentro de la red de gestión pública del turismo. 


\section{ANÁLISIS DE LA OFERTA Y LA DEMANDA TURÍSTICA}

La oferta turística de alojamiento del área compuesta por los 23 municipios concentra en 2017 el 11,3\% de los establecimientos de alojamiento turístico de la Comunidad de Madrid y el 6\% de las plazas (sin contar con el municipio de Madrid). Según datos del Instituto de Estadística de la Comunidad de Madrid (IECM), la oferta se divide según tipología en 19 hoteles, 11 pensiones, 16 hostales, 3 apartamentos, 1 camping y 39 Alojamientos de Turismo Rural entre los que se encuentran 24 Casas Rurales, 6 Hoteles Rurales y 9 Apartamentos Rurales. En total, suman 3.381 plazas de las cuales 767 se ubican en ATR. Como novedad, cabe destacar la presencia también en este territorio de viviendas de uso turístico que aquí pivota sobre la oferta de residencias secundarias de tipo chalé adosado o aislado: son 32 según el IECM. En la web Airbnb.com se anuncian 68 alojamientos, pero en su mayoría se incluye la oferta reglada en apartamentos, hostales y casas rurales, y solo algunas habitaciones y alojamientos completos en viviendas de particulares. Si se contrastan los anuncios de esta plataforma con el parque residencial secundario (unas 8.000 viviendas según el Censo de 2011, un 22\% del total residencial), la orientación hacia el alquiler vacacional es en este espacio completamente residual.

La variación temporal 2008-2017 (2008 es el primer año en que el IECM expone los datos) del número de establecimientos y de plazas en la comarca muestra una tendencia de leve crecimiento contando con un periodo bastante estable desde 2011 hasta 2016, aunque a partir de ese último año se da una tendencia de fuerte crecimiento (ver Figura 6). En el periodo de estudio (2008-2017) se observa una extensión espacial y cuantitativa de la oferta de alojamiento debido a la apertura de los establecimientos y a la ampliación de la capacidad de los existentes, incluso sin contabilizar las plazas en VUT: algunos municipios estrenan alojamiento en 2009 (Valdelaguna), 2010 (Villar del Olmo) y 2013 (Valdaracete), y otros incrementan su número paulatinamente en 2010 (Aranjuez), 2011 (Villarejo de Salvanés), 2012 (Colmenar de Oreja), 2016 (Ciempozuelos, Estremera y Valdelaguna) y de forma más acusada en 2017 (Aranjuez, Carabaña, Chinchón, Ciempozuelos, Colmenar de Oreja, Morata de Tajuña, Tielmes, Valdaracete, Valdelaguna y Villarejo de Salvanés). En definitiva, la comarca tiene actualmente capacidad para absorber hasta 1.234.065 de pernoctaciones anuales, de las cuales 279.955 utilizarían plazas en ATR.

Los ATR son aquellos que mayor impulso han experimentado, en particular, en el periodo 2006-2014 y en el área compuesta por los 21 municipios receptores de fondos LEADER. Según el diagnóstico comarcal del GAL Aracove (Red2Red Consultores, 2015), se aprecia un aumento del 72,9\% del alojamiento, que llega al 500\% en el caso de los ATR. Del mismo modo, las plazas han aumentado un 58,9\% y un 540\% en particular en los ATR. A partir de 2011 se estanca la apertura de alojamientos y la creación de nuevas plazas, por lo que el periodo de máximo crecimiento se restringe a 2006-2010 coincidiendo con el final de LEADER+ y el arranque del eje LEADER.

La variación espacial de la oferta de alojamiento turístico refleja la dualidad del funcionamiento territorial con una excepción: el municipio de Chinchón. De un lado, Aranjuez, Ciempozuelos y San Martín de la Vega, municipios urbanos de mayores densidades, destacan por la concentración de plazas, fundamentalmente hoteleras muy relacionadas con su posición de borde metropolitano. De otro, el resto de los municipios alberga un número 
de plazas menor en su conjunto. Chinchón emerge como una realidad singular en la que destaca por tener el mayor número de alojamientos (37) y ocupar el segundo puesto en número de plazas (510) por detrás de Aranjuez. Le siguen municipios como Valdelaguna, Colmenar de Oreja, Valdilecha, Villarejo de Salvanés, Fuentidueña y Carabaña (destaca la presencia de ATR). Se produce después una reducción progresiva de la oferta turística hacia el extremo oriental de la comarca. Los municipios con presencia anecdótica de alojamiento se relacionan con pensiones y hostales destinados a trabajadores temporales de la agricultura o la industria cementera de la zona.

\section{Figura 6}

\section{EVOLUCIÓN DEL NÚMERO DE ALOJAMIENTOS Y DE PLAZAS TURÍSTI- CAS EN LA COMARCA (23 MUNICIPIOS) DESDE 2008 HASTA 2017 DETA- LLANDO LOS CASOS DE ARANJUEZ Y DE CHINCHÓN}

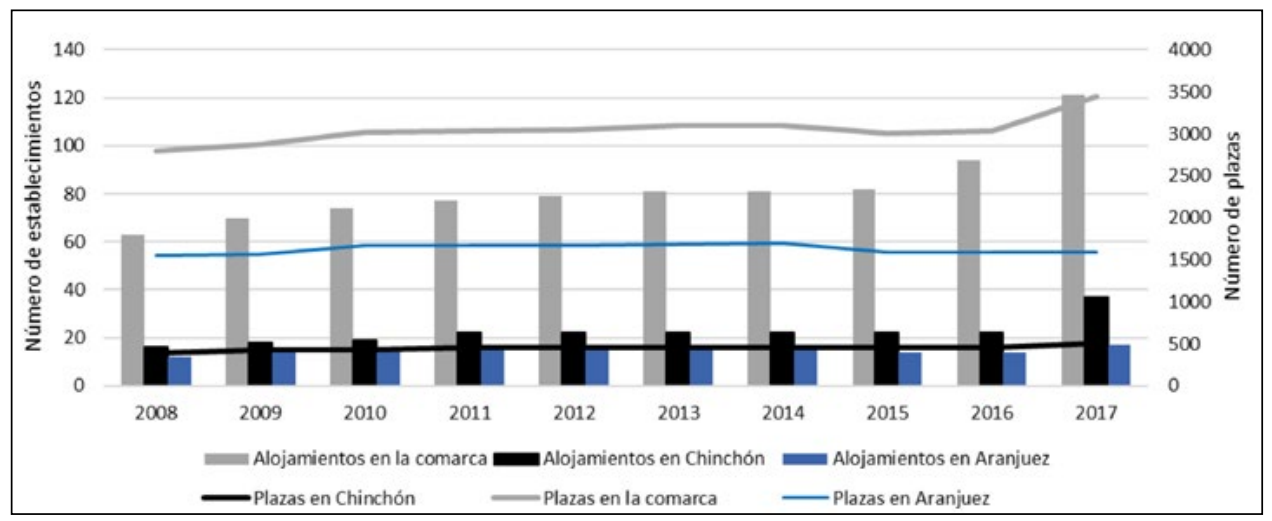

Fuente: Banco de datos Almudena, Comunidad de Madrid.

En términos de demanda turística no hay apenas información disponible. Haciendo una estimación simple a partir de los datos de las Encuestas de Ocupación del INE (EOH, EOA y EOATR), puede considerarse que, en el año 2017, la Comarca de las Vegas acogió en sus alojamientos a 225.629 turistas que realizaron 487.435 pernoctaciones aproximadamente; de éstas, 30.197 y 57.685 respectivamente corresponderían a los ATR. Esta estimación se basa en la relación oferta y demanda anuales de la Comunidad de Madrid y la aplicación de su proporción a los datos de la Comarca de las Vegas. En cualquier caso, estos datos son muy inferiores a la capacidad de alojamiento real antes referida.

Por su parte las consultas efectuadas en las OIT recogen también cifras inciertas. La comarca alberga 4 Oficinas de Información Turística adheridas a la red de OIT de la Comunidad de Madrid en Aranjuez, Chinchón, Colmenar de Oreja y Villarejo de Salvanés. De hecho, a excepción de Aranjuez y Chinchón el resto de OITs, por su reciente creación, y a pesar de los esfuerzos en garantizar una apertura continuada, tienen menor capacidad para realizar recuentos exhaustivos, aunque registren un menor número de visitas. A pesar de esta limitación, la información disponible permite conocer su evolución reciente (ver Figura 7). 


\section{Figura 7 \\ CONSULTAS REGISTRADAS EN LAS OFICINAS DE INFORMACIÓN TURÍS- TICA (2010-2017)}

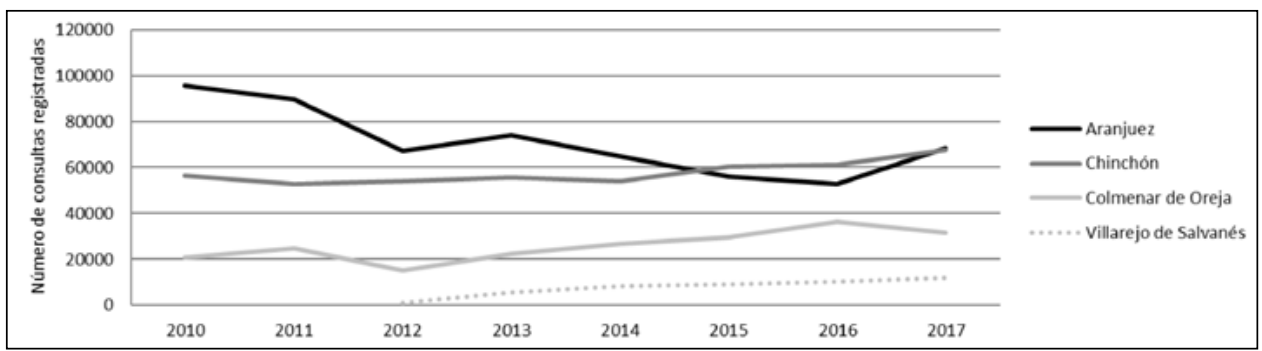

Fuente: Ayuntamientos de Aranjuez, Chinchón, Colmenar de Oreja y Villarejo de Salvanés.

En primer lugar, se sitúa la OIT de Aranjuez con un total de 68.362 consultas en 2017, un $30 \%$ más que el año anterior, dando fin a un periodo de decrecimientos anuales del 28,6\% (2010-2017). Le sigue Chinchón que ha registrado un número muy similar de consultas, 67.451, en 2017. Sin embargo, la tendencia de esta localidad en el periodo observado es al alza (19,3\%). Después, Colmenar de Oreja ha alcanzado las 31.469 consultas, creciendo un $37,6 \%$. Por último, Villarejo ha registrado 11.903 , un $110 \%$ más de lo que registró en 2013, primer año en que se tienen datos completos tras la apertura de su OIT.

Estas cifras presentan varias limitaciones a la hora de dar una imagen completa del número de visitantes que acuden a estos lugares, pues no se incluyen aquí aquellas personas y grupos que no acuden a las OIT, por ejemplo, en el caso de segundas y sucesivas visitas. En Aranjuez es preciso considerar además el número de entradas al Real Sitio, que concentra en torno a un 90\% de las visitas al municipio (Mínguez 2007 citada en Velasco, 2015). Así, en 2017 se alcanzaron las 293.287 entradas en el Palacio Real y 849.234 en el Jardín del Príncipe, de entrada gratuita y espacio de ocio local con uso muy intensivo. Si se tiene en cuenta que se estima en torno a un 9,4\% los visitantes de Aranjuez que no entran en el Palacio (Troitiño Vinuesa et al., 2011), el número de visitantes aumentaría, al menos, hasta los 320.000 en 2017. En Chinchón, el estudio de demanda más completo de que dispone la OIT (Comunicación y Consultoría Turística, 2001) apuntaba entonces a que solo el $20 \%$ de los visitantes acudían a la oficina, por lo que se esperaría que el número real fuera un $80 \%$ mayor, es decir en 2017 de 340.000 aproximadamente. Algunas noticias de prensa elevan también entre 200.000 y 300.000 el número de visitantes reales en un año (Pérez, 2013).

La desagregación de los datos de consultas de 2017 por procedencias arroja un elevado porcentaje de visitantes del entorno autonómico propio del funcionamiento turístico de la región (ver Tabla 1). Así, en Aranjuez, el 83,5\% de las consultas se realizaron por residentes en España de los cuales el 50,6\% provenían de la propia Comunidad de Madrid. Estas cifras son más elevadas en Chinchón: $89,6 \%$ y 58,7\% respectivamente. El número de consultas realizadas por madrileños aumenta en el periodo 2010-2017 en Chinchón $(26,1 \%)$ pero se reduce en Aranjuez $(-15,8 \%)$. En términos relativos, sin embargo, los 
madrileños pasan a ocupar una parte más importante del total de las consultas en Aranjuez (del 42,8 al 50,6\%) y en Chinchón pasan a ocupar una parte más reducida (del 65,3 al $58,7 \%$ ), pues crecen las visitas de otros residentes del país.

En cuanto al turismo receptor, en Aranjuez las 10.940 consultas realizadas por residentes en el extranjero en 2017 suponen un 16,4\% del total de consultas. Un porcentaje inferior ofrece Chinchón donde las 6.985 consultas realizadas suponen el 10,3\% del total. En el resto de las oficinas, el porcentaje es muy inferior, apenas un $1 \%$ de las consultas realizadas en Colmenar proceden de residentes en el extranjero mientras que en Villarejo son prácticamente nulas. Las consultas realizadas por los residentes en el extranjero se reducen en el periodo 2010-2017 tanto en Aranjuez como en Chinchón en torno a un 40\%, solo aumentan en Colmenar, aunque sus números absolutos son muy reducidos.

\section{Tabla 1}

\section{DATOS ABSOLUTOS Y RELATIVOS DE LAS CONSULTAS A LAS OFICINAS DE INFORMACIÓN TURÍSTICA DESAGREGADAS POR PROCEDENCIAS}

\begin{tabular}{|l|l|l|l|l|l|l|l|l|}
\hline & \multicolumn{7}{|l|}{ Absolutos } & \multicolumn{7}{l|}{ Relativos } \\
\hline 2017 & $\begin{array}{l}\text { Res. } \\
\text { ES }\end{array}$ & $\begin{array}{l}\text { Res. } \\
\text { CM }\end{array}$ & $\begin{array}{l}\text { Res. } \\
\text { ext. }\end{array}$ & Total & $\begin{array}{l}\text { Res. } \\
\text { ES }(\%)\end{array}$ & $\begin{array}{l}\text { Res. } \\
\text { CM* }(\%)\end{array}$ & $\begin{array}{l}\text { Res. } \\
\text { ext. }(\%)\end{array}$ & $\begin{array}{l}\text { Total } \\
(\%)\end{array}$ \\
\hline Aranjuez & 55512 & 28091 & 10940 & $66452^{* *}$ & 83.5 & 50.6 & 16.5 & 100.0 \\
\hline Chinchón & 60466 & 35515 & 6985 & 67451 & 89.6 & 58.7 & 10.4 & 100.0 \\
\hline Colmenar de Oreja & 31222 & n.d. & 247 & 31469 & 99.2 & n.d. & 0.8 & 100.0 \\
\hline 2010 & $\begin{array}{l}\text { Res } \\
\text { ES }\end{array}$ & $\begin{array}{l}\text { Res } \\
\text { CM }\end{array}$ & $\begin{array}{l}\text { Res } \\
\text { ext. }\end{array}$ & Total & $\begin{array}{l}\text { Res } \\
\text { ES\% }\end{array}$ & $\begin{array}{l}\text { Res } \\
\text { CM\% }\end{array}$ & $\begin{array}{l}\text { Res } \\
\text { ext.\% }\end{array}$ & Total \\
\hline Aranjuez & 77975 & 33393 & 17771 & 95746 & 81.4 & 42.8 & 18.6 & 100.0 \\
\hline Chinchón & 43093 & 28161 & 13443 & 56536 & 76.2 & 65.3 & 23.8 & 100.0 \\
\hline Colmenar de Oreja & 20476 & n.d. & 81 & 20557 & 99.6 & n.d. & 0.4 & 100.0 \\
\hline
\end{tabular}

Nota: * Se refiere al porcentaje de consultas realizadas por residentes en la Comunidad de Madrid con respecto al realizado por residentes en el país. ** Se trata del total de las consultas que contestaron a la pregunta sobre procedencia.

Fuente: Ayuntamientos de Aranjuez, Chinchón y Colmenar de Oreja.

En cuanto a la distribución anual de las consultas en las OIT con datos disponibles, Aranjuez, Chinchón y Colmenar de Oreja apuntan máximos en primavera (especialmente durante el periodo festivo de la Semana Santa) y en puentes. Aranjuez destaca por dibujar un perfil más internacional con repuntes en agosto, mientras que en Chinchón y Colmenar destacan solo los repuntes durante los puentes de primavera, otoño e invierno (ver Figura 8). 


\section{Figura 8 \\ DISTRIBUCIÓN ANUAL DE LAS CONSULTAS EN OFICINAS DE INFORMACIÓN TURÍSTICA (2017)}

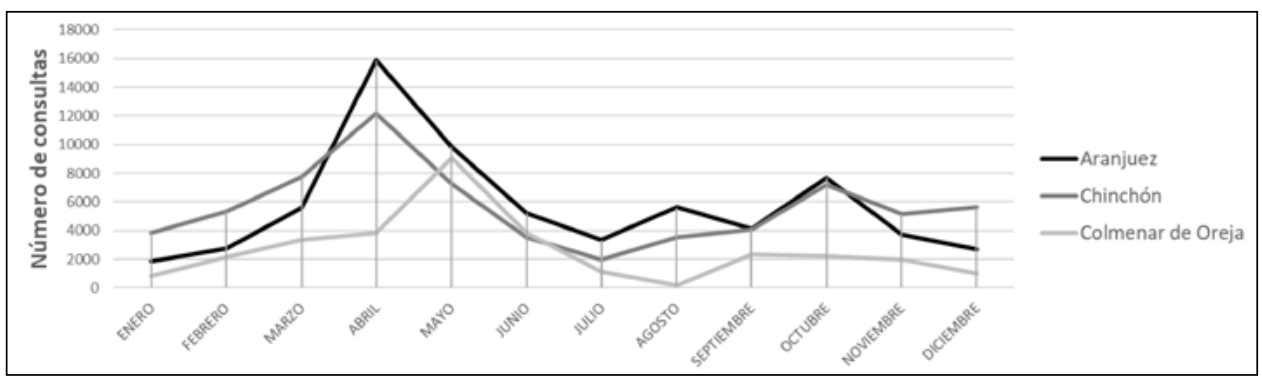

Fuente: Comunidad de Madrid.

Por todo lo visto hasta ahora, la dualidad occidental/oriental a la que está sometido el funcionamiento territorial de la comarca resulta también turística, aunque en este ámbito se reconocen algunos matices. Aranjuez es sin duda el gran nodo de atracción turística. De rango urbano, concentra un patrimonio de valor universal que propicia la atracción de un flujo mayor de visitantes y turistas, más internacional, y la creación de una oferta de alojamiento de mayor capacidad relativa. Ciempozuelos y San Martín de la Vega concentran una oferta importante pero su perfil turístico no se relaciona con el patrimonio, sino que está completamente condicionado por su posición accesible de borde metropolitano, así como por la ubicación del Parque Temático. El sector oriental está dominado por pequeñas localidades de rango rural y de funcionamiento turístico incipiente, aunque muy reducido en el mejor de los casos, y prácticamente limitado a una diminuta oferta de alojamiento en otros. Dadas las características del funcionamiento turístico del sector occidental, el análisis se basa en los 21 municipios del sector oriental donde Chinchón es la gran excepción pues, con apenas 5.000 habitantes, arroja unos índices de especialización turística llamativos (ver Tabla 2). Chinchón encabezaría así el funcionamiento turístico de la comarca rural cuyos límites coinciden con los de LEADER en el periodo 2007-2013.

Tabla 2

DATOS DE POTENCIA Y ESPECIALIZACIÓN TURÍSTICA

\begin{tabular}{|l|l|l|l|l|l|l|l|}
\hline \multicolumn{1}{|c|}{2017} & $\begin{array}{c}\text { Hab. } \\
\text { (INE) }\end{array}$ & $\mathrm{N}^{\circ}$ plazas & $\begin{array}{c}\text { Plazas/ } \\
1.000 \text { hab. }\end{array}$ & \multicolumn{1}{c|}{$\begin{array}{c}\mathrm{N}^{\circ} \\
\text { restaurantes }\end{array}$} & $\begin{array}{c}\text { Restaurantes/ } \\
1.000 \text { hab. }\end{array}$ & $\begin{array}{c}\text { Consultas } \\
\text { OIT }\end{array}$ & $\begin{array}{c}\text { Consultas } \\
/ 1.000 \text { hab. }\end{array}$ \\
\hline Aranjuez & 58.213 & 1.593 & 27,4 & 95 & 1,6 & 68.362 & $1.174,3$ \\
\hline Chinchón & 5.240 & 510 & 97,3 & 29 & 5,5 & 67.451 & $12.872,3$ \\
\hline Colmenar & 7.810 & 93 & 11,9 & 7 & 0,8 & 31.469 & $4.029,3$ \\
\hline Villarejo & 7.245 & 58 & 8 & 10 & 1,3 & 11.903 & $1.642,9$ \\
\hline
\end{tabular}

Fuente: INE, Banco de datos Almudena, Comunidad de Madrid, contrastado con información municipal actualizada (I-2018). 


\section{LA ARTICULACIÓN DE UN DESTINO RURAL DE BASE COMARCAL EN EL SURESTE DE MADRID}

\subsection{Programas que inciden en el reequilibrio territorial del turismo en la Comuni- dad de Madrid}

El sector oriental de la Comarca de las Vegas, exceptuando Chinchón, no ha sido un territorio tradicionalmente turístico, sino que las iniciativas de desarrollo de esta actividad han provenido de los instrumentos de la Política de Desarrollo Rural como los programas LEADER y su homólogo PRODER. Los programas de la Dirección General de Turismo de la Comunidad de Madrid son más recientes. De este modo, la disponibilidad de los fondos públicos sirve para la financiación de una amalgama de actuaciones.

En la comarca se constituyó la Asociación ARACOVE en 1996. Fue uno de los primeros 23 territorios nacionales en aplicar el programa LEADER y en la actualidad es uno más de los más de 250 con los que cuenta el país. LEADER y PRODER se aplican conjuntamente en la Comunidad de Madrid hasta el año 2006, momento en que desaparece este último. Aunque en las sucesivas estrategias locales de desarrollo (principal documento que guía la implementación de estos instrumentos) el turismo aparece mencionado como una oportunidad estratégica para acceder a nuevos mercados de consumidores y diversificar la economía rural, lo cierto es que las actuaciones han respondido en realidad a la demanda en equipamientos públicos, a la promoción de rutas comarcales y a la apertura de ATR. PRODER 2 fue el que más ha influido en el aumento de la capacidad de alojamiento abriendo entre 2002 y 2006 alrededor de 195 plazas de alojamiento turístico en 9 municipios de la comarca donde la oferta era hasta el momento inexistente; mientras el GAL editaba guías comarcales con ayuda LEADER. A partir de 2007 arranca la apertura de equipamientos (como el centro de interpretación del yacimiento Risco de las Cuevas en Perales y el Museo de la Tercia en Villarejo). En total, se financian en 2007-2013 apenas 12 actuaciones de desarrollo turístico de las 101 ejecutadas, pero llegan a alcanzar casi el 19\% de la subvención. Los proyectos aprobados en 2017 siguen esta tendencia: en las primeras convocatorias (de 2017) seleccionan 6 proyectos turísticos de los 20 totales, pero llegan a acaparar 52,8\% del total subvencionado. Por tanto, escasa demanda de proyectos turísticos, pero que absorben una mayor parte de la financiación. En la actual edición de LEADER (14-20), el GAL ofrece un renovado apoyo al turismo al priorizar aquellos proyectos que complementen los productos turísticos impulsados por la Comunidad de Madrid (Bases reguladoras, v.09) y al ponerse en marcha el primer proyecto de cooperación con el resto de GAL de la Comunidad de Madrid denominado "Madrid Destino Rural" y financiado íntegramente por LEADER. A pesar de que los proyectos han sido y siguen siendo más numerosos en las medidas de mejora de las empresas agroindustriales y los servicios locales, los proyectos de tipo turístico siguen acaparando un mayor volumen de financiación.

De otra parte, en relación con la política turística autonómica, la Dirección General de Turismo, con el apoyo de otras fórmulas de gestión público-privada, ha asumido competencias en la coordinación, fomento y planificación del sector y de la actividad turística, con especial atención a la promoción y la ordenación (art. 6 de la Ley 1/1999, de 12 de marzo, de Ordenación del Turismo de la Comunidad de Madrid). La actuación del Gobierno auto- 
nómico directamente sobre los territorios locales se ha desarrollado a partir de las convocatorias de subvenciones para material promocional, el establecimiento de la Red autonómica de OIT "Mad About Info" y el fomento de la planificación local. En este sentido, en los años anteriores a la crisis económico-financiera los planes en destino de la Comunidad de Madrid fueron el principal instrumento sobre el que pivotó la actuación autonómica con carácter territorial. Estos planes imitaban los planes en destino de la política turística nacional creados desde los años 90. En la zona han tenido aplicación tres planes en destino. Los dos primeros fueron dos planes Microdestino aplicados a Chinchón y a la mancomunidad Sureste (MISECAM) en 2007-2008. La principal actuación que perdura fue la rehabilitación del antiguo matadero de Chinchón cuyo uso hoy no se relaciona con el turismo, es Casa de la Cultura y sede del GAL ARACOVE. El tercero fue un Plan de Competitividad del Producto Turístico (2011-2015) que, tras varias solicitudes fallidas, les fue otorgado entre los once últimos planes concedidos a nivel nacional. La firma del convenio entre Turespaña, la Consejería de Economía y Hacienda de la Comunidad de Madrid, el Ayuntamiento de Chinchón y la Agrupación Hostelera y de la Industria Turística de Chinchón tuvo lugar en 2011. El Convenio tenía una duración de 4 años, y en abril de 2015 se publicó una adenda que reducía el cuadro de actuaciones y su presupuesto financiero. Con el cambio de gobierno y de corporación municipal, se dio el plan por finalizado. Las actuaciones llevadas a cabo por este Plan resultaron ser menos de las inicialmente previstas.

A partir de la crisis económica y en el marco del Plan de Turismo de la Comunidad de Madrid 2013-2015, arrancó un proceso de creación de productos turísticos por parte de la DG de Turismo con el fin de articular una oferta que conectara los tres vértices de la región con los flujos turísticos que existen en la Comunidad. Así, se inició el programa Villas de Madrid (2013) para articular una serie de descuentos en los establecimientos adheridos de Chinchón, Colmenar de Oreja y Villarejo de Salvanés, adherido este último en 2015 (ver Figura 9). Posteriormente, se desarrolló el programa Ciclamadrid (2014) que despliega un anillo ciclista de $471 \mathrm{~km}$ a unos $50 \mathrm{~km}$ de Madrid y mediante el que se promocionan $60 \mathrm{~km}$ en la Comarca de las Vegas y otras pequeñas rutas ciclistas que discurren por las Vías Verdes del Tajuña y del "Tren de los 40 días". En la zona sureste todas las rutas se articulan a la oferta patrimonial y enogastronómica. Estos programas se han extendido en las Estrategias de Turismo de la Comunidad de Madrid 2016-2019 y el Plan Regional de Turismo Sostenible 2017-2019.

A esta labor programática, se unen otros dos instrumentos elaborados por otras Direcciones Generales. En primer lugar, el programa Madrid Enoturismo (2013), antiguo Madrid Rutas del Vino, impulsado por la Dirección General de Medioambiente de la Comunidad de Madrid y el Consejo Regulador de la D.O. Vinos de Madrid, con el apoyo de la Asociación de Ciudades Españolas del Vino (ACEVIN). La zona de estudio se denomina "Subzona de Arganda" y es la más importante en términos vitivinícolas y de empresas adheridas con 13 de las 27 bodegas de la Comunidad adscritas a la DO (ver Figura 10). Y, en segundo lugar, el Plan de Yacimientos Visitables (2003) y posterior Plan de Fortificaciones de la Guerra Civil 1936-1939 (2017) impulsado por la Dirección General de Patrimonio Cultural. Están incorporados el yacimiento carpetano-romano de Titulcia y el Risco de las Cuevas en Perales cuyas fases de estudio culminaron con la apertura de un museo y un centro de interpretación respectivamente. 


\section{Figura 9 \\ LA PLAZA MAYOR DE CHINCHÓN ES PORTADA DE LA WEB PROMOCIONAL DE "VILLAS DE MADRID"}

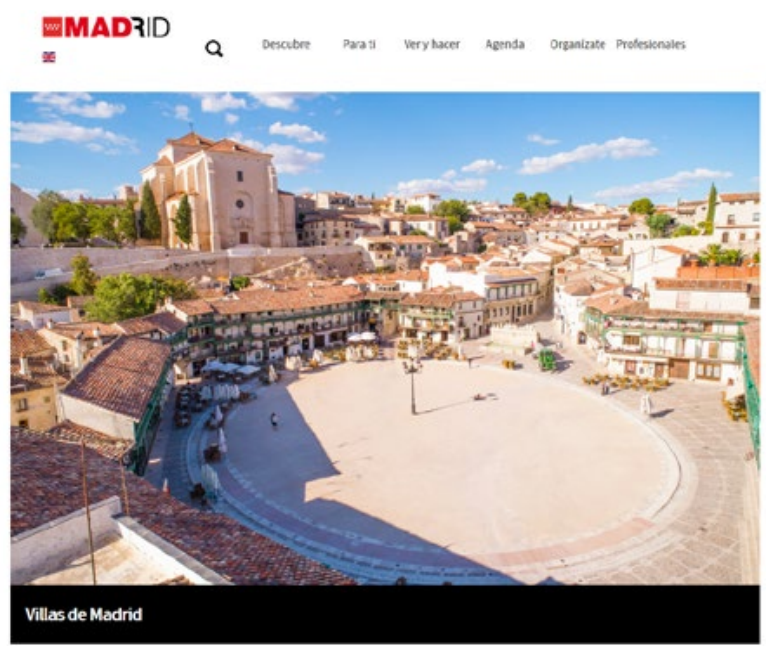

Fuente: https://turismomadrid.es/es/portada/10374-villas-de-madrid.html

\section{Figura 10 \\ SUBZONAS DEL PROGRAMA "MADRID ENOTURISMO"}

Leyenda: el color naranja se corresponde con la subzona de Arganda (donde se incluye el área objeto de estudio), el rojo con San Martín de Valdeiglesias y el verde con Navalcarnero. Los puntos morados se corresponden con los establecimientos adheridos.

Fuente: http://madridenoturismo.org/los-vinos-de-madrid/ 


\subsection{La adhesión de agentes públicos y privados a los programas}

\subsubsection{La adhesión hacia los instrumentos de iniciativa suprarregional LEADER y Planes en Destino}

LEADER cuenta con la adhesión formal de todos los ayuntamientos del territorio a través de su participación como socios en la Asamblea General, pero su adhesión real hacia el desarrollo turístico a través de este instrumento es muy variable. En el ayuntamiento de Chinchón, la OIT no colabora pues afirman "No conocemos sus estrategias, pero sabemos que no se relacionan con el turismo" (OIT Chinchón, 22/06/17). Igualmente, la OIT de Colmenar valora de "agrarista" la estrategia de desarrollo local del GAL y afirma que "no consigo arrancar con ellos", pero reconoce el potencial que tiene la organización para liderar el desarrollo turístico comarcal (OIT Colmenar de Oreja, 27/07/17). Sin embargo, el resto de los municipios entrevistados muestra una idea diferente de la estrategia "el turismo en Aracove tiene mucho peso. Se ve enseguida por las partidas presupuestarias que le reservan a la medida 313 [fomento del turismo en el eje LEADER] en las convocatorias" (ADL Valdilecha, 19/06/2018). Y muestran un fuerte apoyo a la labor del GAL en materia turística, especialmente en la promoción de la comarca en su conjunto (OIT Villarejo de Salvanés, 18/06/18) y de los municipios en particular como Perales o Valdilecha (ADL Perales, 16/02/19). Concretamente, la ADL de Valdilecha se ha implicado en la elaboración de una estrategia turística municipal que finalmente no salió resuelta: "Consistía en homogeneizar la señalización, realizar vuelos para tomar fotografías promocionales, incorporar paneles en varios recursos con códigos $Q R$, trazar rutas urbanas... Tenía de todo. [...] Era precioso, integral, unía tradición y nuevas tecnologías. [...] Lamentablemente el proyecto iba cojo, ya lo sabía yo, y no pudo ser seleccionado. [...] Yo quiero que salga [en la próxima convocatoria], a mí me encantan estos temas, pero ni soy técnico de turismo, ni tengo tiempo" (19/06/2018). En el otro extremo, el ayuntamiento de Morata de Tajuña, recientemente excluido del territorio LEADER por superar el umbral de densidad permitido, muestra desafección por el programa "Aracove solo está para los pequeños municipios, (...) el beneficio económico se lo llevan siempre ellos".

En cuanto al sector empresarial asociado, todos perciben el GAL como útil, incluso imprescindible (Federación de empresarios de la comarca, 31/07/17) y se muestran muy cercanos tanto laboral como personalmente. El ex presidente de la asociación de empresarios turísticos de Chinchón afirma tener "una relación muy estrecha. Soy socio desde hace muchos años (como empresario particular)" y otro miembro de la misma asociación "era amiga del antiguo gerente. Siempre me han ayudado" (Alojamientos de Turismo Rural en Chinchón, 27 y 28/06/18). El sector empresarial no asociado varía en su opinión, aunque nunca es negativa, el grado de adhesión oscila entre la mera información sobre las subvenciones disponibles hasta la buena experiencia tras haber sido beneficiarios. Dos empresarias del sector turístico de Morata y Chinchón se muestran desconocedoras de la labor del GAL. Al respecto, la proximidad geográfica no parece jugar un papel tan importante para su conocimiento como el ritmo con el que se abren las convocatorias de subvención. 
La valoración del Plan de Competitividad Turística de Chinchón es altamente controvertida. Desde el ayuntamiento aseguran que, tras la ejecución de todas sus partidas (modificada por adenda en abril de 2015), el Plan finalizó con éxito (Ayuntamiento de Chinchón, 27/07/17). La opinión del departamento de Desarrollo Local, encargada de elaborar la lista de actuaciones a realizar en 2011, de modificarlas para la adenda en 2015 y de justificarlas para su cierre, y de la OIT, es algo diferente, pues reconocen que se cerró sin que la inversión hubiera sido tal y como se acordó para cada partida.

La visión de la asociación de empresarios turísticos que firma el convenio en 2011 , también crítica, está profundamente marcada por la decepción de este inicial proceso de colaboración público-privado y a varias escalas. La percepción que tienen de las carencias del Plan, tanto la Junta Directiva de 2011 como la siguiente que lo vio terminar, se relaciona con deficiencias en el proceso de participación desde el inicio hasta el cierre: "contactaron con la asociación cuando el plan ya apalabrado con la Comunidad de Madrid [por el ayuntamiento]” (Asociación de Turismo de Chinchón), 28/06/18), "desde que se inició, no hubo reuniones en condiciones. La comunicación era muy deficiente entre el ayuntamiento y la asociación" (Asociación de Turismo de Chinchón, 27/07/17), “A día de hoy, la asociación no ha recibido ninguna notificación por escrito [de su cierre]" (Asociación de Turismo de Chinchón, 27/07/17). Aunque el presidente de la asociación y firmante del convenio opina que era ambicioso y muy positivo para Chinchón, también considera que su ejecución estuvo marcada por intereses del partido político que coincidía en el ayuntamiento, la Comunidad y el Ministerio (28/06/18).

\subsubsection{La adhesión hacia los programas de la Dirección General de Turismo}

"Villas de Madrid" es el programa vigente más antiguo que existe en la comarca en el que participan Chinchón y Colmenar de Oreja desde 2013 y Villarejo de Salvanés desde 2015. Las tres OIT y el GAL muestran desafección hacia éste por considerar que no ha funcionado la comunicación con los agentes privados de la zona, el dispositivo propuesto, primero tarjeta y después aplicación móvil, ni la evaluación del programa.

“Está consolidado, pero no funciona. La aplicación móvil no funciona. Además, tampoco se sabe el nivel de uso que tiene esa aplicación. [...] El problema fue que no contactaron con las OIT, ni con los empresarios. Las bases no estaban claras... no se sabía a cuántas personas se les debía aplicar el descuento, si al propietario de la tarjeta, al acompañante o a cuántos. Hicieron unas reuniones aquí para presentar la tarjeta a los hosteleros, pero no supieron contestar a muchas de sus preguntas" (OIT Chinchón, 22/06/17).

Se añade el descontento en la OIT y el departamento de Desarrollo Local por haber equiparado Chinchón al rango del resto de villas de la zona. Para la OIT de Colmenar de Oreja, el programa "funcionaba bien con nuestro perfil de visitante (40-65 años), pero al cambiar al sistema de aplicación móvil, no funciona con ese perfil [más joven que usa las aplicaciones]" (27/07/17). La OIT de Villarejo pidió información sobre la evaluación del programa a incorporarse y "nos dijeron que no tenían nada" (18/06/18). El sector privado 
alude también a una conceptualización del producto alejada de las prácticas turísticas reales: "era un lío (...) rompía la lógica de la reserva inmediata que tienen que seguir los negocios." (Casa Rural Chinchón, 28/06/18); "Cuando impusieron el procedimiento vía Smartphone, no todos teníamos uno" (Bodega Colmenar de Oreja, 29/06/18); "No funciona. A la siguiente reunión, no acudirê"' (Restaurante Villarejo de Salvanés, 18/06/18).

El más reciente, Ciclamadrid, goza de una adhesión muy dispar. La OIT de Colmenar de Oreja, que demuestra un alto grado de implicación, hace pivotar su estrategia turística local sobre este proyecto que logra articular a la oferta enoturística de la zona. Por ello, lo califica de muy positivo (OIT Colmenar de Oreja, 27/07/17). Desde Chinchón, se teme que se trate de "otro demasiado gran proyecto" (OIT Chinchón, 22/06/17), y en Villarejo de Salvanés se desconfía de que pueda funcionar porque "los ciclistas a los que va dirigido no funcionan en esa lógica de gran ruta" (OIT Villarejo de Salvanés, 18/06/18). También, desde el GAL se advierte que su fracaso: como el resto de los proyectos impulsados por el sector público, depende de que los empresarios se interesen y se encarguen de su mantenimiento y dinamización (GAL, 16/02/19). Al otro extremo, el Centro de Recepción de Visitantes del Parque Regional no ha oído hablar del proyecto hasta el momento de la entrevista a pesar de que las rutas lo atraviesan en parte (PRSE, 06/07/17).

\subsubsection{La adhesión hacia los programas liderados por otras Direcciones Generales}

El Plan de Yacimientos Visitables no genera adhesión a nivel comarcal sino a nivel municipal allí donde se ubican éstos. El Parque Regional del Sureste ofreció visitas al Centro de Interpretación Arqueológica de Titulcia, pero solo durante un año. El Centro de Interpretación Risco de las Cuevas de Perales sirve casi exclusivamente de actividad complementaria para el ATR de la localidad. El nuevo Plan de Fortificaciones de la Guerra Civil, sin embargo, es la base de la estrategia turística de Morata que ya se desarrollaba en torno a la temática de la Guerra Civil fundamentalmente a través de las Jornadas de la Batalla del Jarama desde 2011 que incluyen conferencias, visitas guiadas y una recreación histórica, y de un museo privado en un restaurante desde 2018. Cabe destacar el interés del ayuntamiento en crear una oferta más estructurada en torno a la iniciativa de Parque Histórico de la Batalla junto con San Martín de la Vega, Rivas Vaciamadrid y Arganda del Rey. La implicación del ayuntamiento de Morata en adecuar el Plan de Fortificaciones a sus objetivos de desarrollo de este segmento es importante, habida cuenta de la implicación personal de su concejal de cultura como presidente de la Asociación de la Batalla del Jarama (Ayuntamiento Morata de Tajuña, 25/06/18).

"Madrid Enoturismo" es un proyecto renovado que despierta el interés de los municipios para diversificar la actividad de las bodegas y que éstas encuentren líneas de financiación y nuevos mercados. La estrategia turística de Colmenar de Oreja trabaja con la línea de enoturismo como una de las líneas principales y "de mayor potencial" (OIT Colmenar de Oreja, 27/07/17), tanto para ofrecer rutas temáticas en el marco de Ciclamadrid, como para animar a las bodegas a adherirse a este programa. Así lo demuestra que se trata de la localidad con mayor número de bodegas adheridas: son 3 de las 7 con D.O. Vinos de Madrid y de las 5 que están adheridas al Sistema nacional de Calidad en Destino (SICTED). Para su técnico de turismo "todas las bodegas en SICTED están 
muy interesadas en adherirse al programa" (27/07/17). El ayuntamiento de Morata de Tajuña se ha incorporado recientemente en 2017 con cierta confianza de "un proyecto que avanza lento" por la fuerte competencia de otras D.O. españolas, pero hacia el que se muestra muy favorable por su potencial capacidad para arrastrar otros sectores como la hostelería y la artesanía. El interés de la Corporación Municipal es tal que activó los lazos familiares y de amistad existentes con los propietarios de la bodega con D.O. para persuadirla, con éxito, de su incorporación (Morata de Tajuña, 25/06/2018). También el equipo gestor del Centro de visitantes del Parque Regional del Sureste trabaja con la única bodega de Titulcia adherida. En general, "hemos intentado contactar con las bodegas y otros productores, pero al estar fuera del Parque, la Consejería no nos lo permite. El perímetro es un criterio restrictivo" (PRSE, 06/07/17).

Sin embargo, predomina en el sector bodeguero una cierta inercia negativa en cuanto a la implementación de productos turísticos venidos "de arriba". Uno de los socios afirma "[Madrid Enoturismo] no funciona. Lo trajeron aquí diciendo que era "una plataforma", "un motor" de cooperación para atraer a más visitantes pero lo cierto es que el mercado es muy fragmentado y no está adaptado a la práctica turística: un turista no va a ver dos bodegas en un día. Y si se va de la zona, no tiene porqué volver" (bodega Colmenar de Oreja, 29/06/2018). Y otro asociado reconoce que, aunque forma parte de la iniciativa, " $n i$ las asociaciones como esta me cambian nada, ni yo a ellos”" (bodega Chinchón, 19/06/18). Del mismo modo, la visión del GAL traduce la aprensión del sector privado hacia un proyecto que requiere demasiado esfuerzo de gestión por parte de los empresarios y que no recogen beneficios a corto plazo (GAL, 16/02/19).

\subsection{La red de gestión pública del turismo}

La explotación de las 18 entrevistas semi-estructuradas realizadas a agentes representantes de entidades públicas y privadas involucradas en la gestión y desarrollo turístico de la comarca ha revelado el bajo índice de relación existente entre los agentes de la zona. El grafo tiene una densidad de 0,14 , lo que significa que se dan solo el $14 \%$ de las relaciones que podrían existir (ver Figura 11).

En el grafo de relaciones destacan dos nodos centrales, la Comunidad de Madrid y, en menor medida, el GAL. Ambos tienen un In-Degree de 9 y 6 respectivamente. La DG Turismo de la Comunidad de Madrid es el agente más conectado en la comarca y es el mejor valorado por los ayuntamientos y OITs de Chinchón, Colmenar de Oreja, Valdilecha y Morata de Tajuña. Sin embargo, aunque conectado por la gestión de algunos programas y ayudas autonómicas, está peor valorado en Villarejo de Salvanés. Por otro lado, el GAL cuenta con el apoyo de los ayuntamientos, basado en su relación orgánica que refleja el interés que encuentran en el GAL como "una oportunidad para el desarrollo de infraestructuras municipales" (GAL, 16/02/19). Es el caso de Valdilecha o de Villarejo cuyas iniciativas turísticas incipientes nacen en el periodo de post-crisis. En el grafo no se reflejan las relaciones que unen al GAL con otras asociaciones empresariales locales o con la federación de empresarios comarcal pues, aunque colaboran estrechamente, se dedican a la comercialización de las producciones locales y no así al turismo. Tampoco la asociación de turismo de Chinchón (ATch) colabora con el GAL a pesar de que sus sedes 
comparten localidad. Entre el GAL y la DG Turismo existe un vínculo reciente a raíz del proyecto de cooperación "Madrid Destino Rural".

Figura 11

GRAFO DE LAS PRINCIPALES RELACIONES ENTRE LOS AGENTES IMPLICADOS EN LA GESTIÓN TURÍSTICA DE LA COMARCA

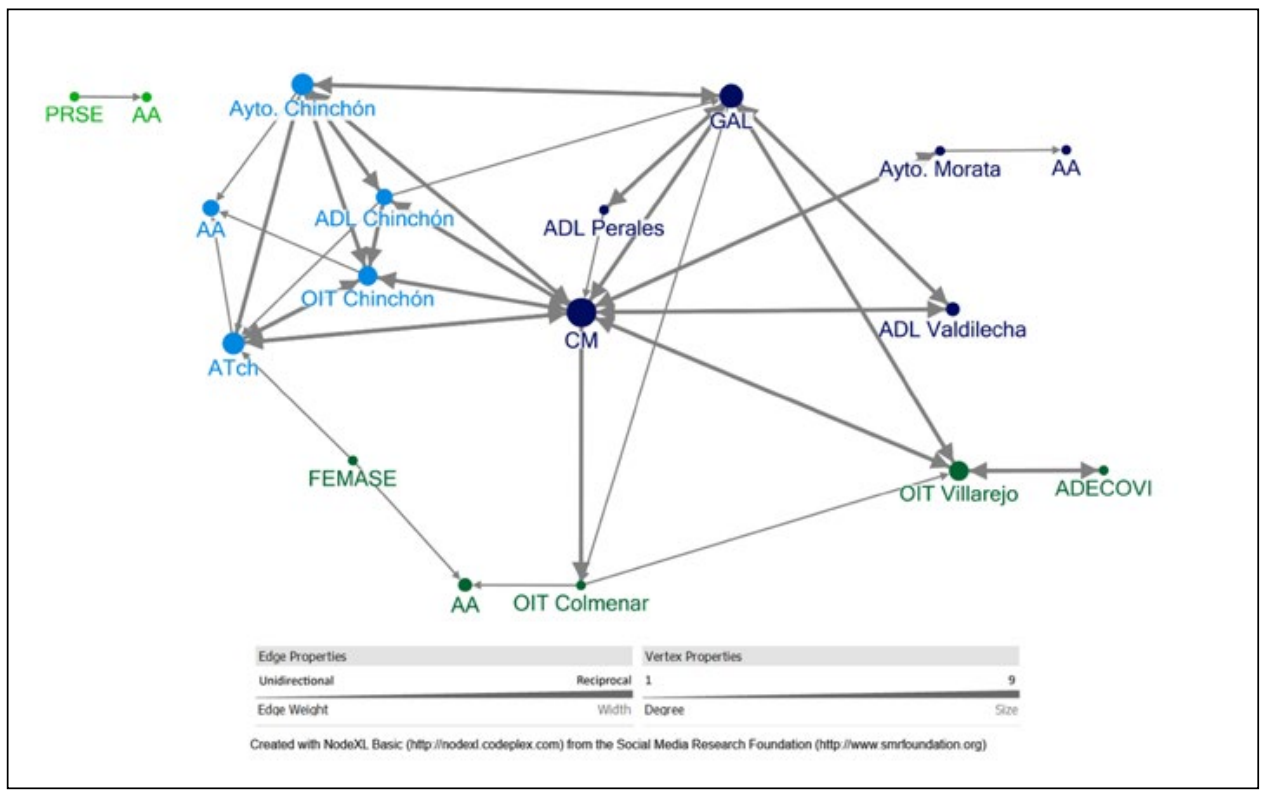

Leyenda: PRSE: coordinadora del Centro de visitantes del Parque Regional del Sureste, ADL: agentes de desarrollo local; Ayto.: ayuntamientos; GAL: gerente del Grupo de Acción Local; CM: Dirección General de Turismo de la Comunidad de Madrid; FEMASE: federación de empresarios del Sureste de Madrid; ATch: Asociación de Turismo de Chinchón; AA: corresponde al resto de asociaciones municipales y de la comarca.

Fuente: elaboración propia.

En el conjunto sobresale un clúster localizado, sin lugar a duda, en el municipio de Chinchón y caracterizado por la densidad de las relaciones internas que provocan un aumento del In-degree de algunos de sus agentes a 5. Así, la consejería de turismo, la OIT y el departamento de Desarrollo Local aparecen fuertemente conectados por una relación orgánica que además se expresa en buenos términos. La asociación de empresarios turísticos del municipio (ATch) colabora con otras asociaciones sectoriales dinamizadoras del turismo en la localidad (relacionadas con la Pasión Viviente y con las visitas teatralizadas fundamentalmente). Se menciona la existencia de varias actuaciones en colaboración con el ayuntamiento y la OIT eminentemente dirigidas a la dinamización de eventos locales, pero valora la colaboración como "pequeña y para actuaciones puntuales" (Asociación de Turismo de Chinchón, 27/07/17). Con el exterior, esta asociación, carece de relaciones fuertes. 
En el resto de la comarca, las relaciones están atomizadas por municipios. Las relaciones intramunicipales se dan entre los ayuntamientos y las asociaciones locales. La relación de los municipios con sus asociaciones culturales para la organización de eventos y otras actuaciones de turismo, según los agentes municipales es muy positiva, no solo en el caso de Chinchón, también de Colmenar de Oreja, Villarejo de Salvanés y Morata de Tajuña. También lo es en el caso del Parque Regional del Sureste que colabora con asociaciones de la zona, aunque ninguna de las mencionadas por los propios ayuntamientos. Sin embargo, más allá de las relaciones intramunicipales, la densidad de la red se muestra débil. Los ayuntamientos, ADL y OIT no exhiben relaciones estrechas intermunicipales, a excepción de Colmenar-Villarejo de Salvanés cuyos proyectos conjuntos como nodos secundarios de atracción de la comarca se encuentran todavía en fase incipiente.

La falta de un "sentido comarcal" se recoge en varios testimonios de los agentes. En términos generales, el GAL advierte de los peligros del cambio de perímetros de su territorio en cada periodo programático:

"Los fondos están siempre condicionados por los perímetros. Los proyectos tardan en arrancar y cuando lo hacen, se quedan obsoletos porque los perímetros ya no incluyen ciertas zonas clave para los proyectos. Por ejemplo, Aranjuez, Morata y Nuevo Baztán: Aranjuez y Morata ya no forman parte de LEADER y en 2014-2020 intentamos incluir Nuevo Baztán, pero la Dirección General [Desarrollo Rural] no quiso, ni siquiera solo el núcleo que no sobrepasa la densidad permitida. Lo ideal sería poder incluirlos en los proyectos de turismo. [...] La identidad territorial está completamente cercenada a raíz de estos cambios. $Y$ ahora más, al incluirse la zona de la Alcarria” (GAL, 16/02/19).

Todos los agentes entrevistados reconocen que el solapamiento de programas de los ayuntamientos, de la Comunidad o del GAL no significa coordinación entre ellos; así como tampoco lo produce la creación y promoción de rutas turísticas. El GAL aparece como el agente más legitimado para promover esta cooperación, sin embargo, no prospera por razones de "inercia" de la comarca, del excesivo límite que suponen los cambiantes perímetros del área, de cierta visión municipalista y, fundamentalmente, por responder a intereses del sector privado alejados del turismo y puestos en otros sectores de la economía como el agrícola y el agroindustrial. Las relaciones del desarrollo turístico se construyen en torno a la Comunidad de Madrid y, fuera de Chinchón, los esfuerzos se centran en conseguir la adhesión de un sector privado local (principalmente alojamientos, bodegas y hostelería) en el que la juventud, en opinión de algunos agentes, es un factor que vuelve a los empresarios más proclives a cooperar. El municipio de Chinchón atrae la actuación del resto de OIT para emprender productos comunes pero una serie de factores impide que prospere: el primero de ellos es el hecho de que el turismo funciona con relativa independencia de las actuaciones públicas acometidas; el segundo es que la política local se centra en la promoción de eventos municipales; y el tercero, se relaciona con una visión general de que su rango patrimonial y turístico es mucho mayor que el resto de localidades de la comarca. 


\section{CONCLUSIONES}

El objetivo de este trabajo ha sido evaluar los principales y más recientes programas llevados a cabo al amparo de la política turística y de la política de desarrollo rural desde el punto de vista de su capacidad para generar un destino de base comarcal. Se ha observado cómo la pretendida extensión de la actividad turística por el territorio comarcal, propiciada por varios programas públicos, no está aún secundada a niveles altos por los agentes comarcales. Esta débil adhesión se materializa, además, en una red de relaciones poco densa y muy polarizada por la Comunidad de Madrid. El argumento de esta investigación plantea cómo el proyecto político tiene importantes limitaciones derivadas del contexto de periferia de borde metropolitano en el que se encuentra el espacio en cuestión. Ahora que la Comunidad de Madrid requiere de la existencia de entidades turísticas interlocutoras en el territorio ${ }^{2}$, cabe preguntarse si es pertinente, viable y qué delimitación debería tener en el sureste de Madrid.

Como en otros casos de estudio, la respuesta territorial ante la llegada de instrumentos de desarrollo turístico enmarcados en las políticas de diversificación de la economía rural como LEADER fue muy positiva en el periodo anterior a la crisis económico-financiera, particularmente a principios de los 2000 (Cànoves, Garay, y Duro, 2012). Este trabajo ejemplifica cómo las periferias turísticas rurales de borde metropolitano también se vieron sometidas a esta dinámica que se conoce como una respuesta exagerada a la creencia en la "panacea turística" por parte de los agentes públicos y a la llegada masiva de fondos para tal fin. Este fomento del desarrollo turístico estuvo guiado por el apoyo del sector público, mientras que el sector privado se orientaba a la ejecución de proyectos de modernización de las instalaciones agroindustriales, de mayor trayectoria y pujanza en la zona. A partir de 2013, un impulso por parte de la Comunidad de Madrid hacia la estructuración de producto mediante la articulación de recursos locales renueva el interés por el desarrollo turístico del GAL. Sin embargo, los nuevos programas de la Comunidad de Madrid se insertan en distintos contextos y se integran en perfiles muy diferentes de desarrollo turístico.

La capacidad que tiene la acción pública turística de componer un destino turístico ampliado en este espacio periférico es muy limitada. Se obtienen dos conclusiones principales al respecto. La primera conclusión parte de la observación de que la adhesión de los agentes hacia los programas varía en función del perfil turístico, de modo que existe diferente grado de adhesión en función de si se trata de Chinchón, Colmenar de Oreja o Villarejo. Chinchón funciona por sí solo por lo que tiene una adhesión baja a estos programas, mientras que núcleos incipientes, como por ejemplo Colmenar de Oreja, tienen una adhesión mayor. Retomando el concepto de "periferias anidadas" puede decirse que los municipios pequeños y de incipiente desarrollo turístico basado en su patrimonio (cultural,

2 La Comunidad de Madrid crea en marzo de 2018 un órgano consultivo denominado "Mesa Regional de Turismo" para mejorar la gestión de sus programas de desarrollo turístico. En esta Mesa, que actualmente está constituyéndose, participan además los ayuntamientos, las asociaciones de empresarios de ámbito regional y los territorios turísticos constituidos en mancomunidades turísticas. Así se promueve la participación de entidades turísticas presentes en las tres periferias turísticas de la Comunidad de Madrid. A falta de una entidad turística en la zona sureste, se acaba de aprobar la presencia de la Comarca de las Vegas como Grupo de Acción Local (febrero de 2019). 
enológico, paisajístico, etc.) apoyan la creación de un destino de base comarcal ya sea a través del GAL o a través de la conexión con Chinchón o entre sí (Colmenar-Villarejo). En estas relaciones de la periferia anidada es donde se encuentran los resultados más optimistas del reconocimiento institucional de estos conjuntos históricos como nodos de atracción turística incipiente. La adhesión de los agentes privados hacia los programas varía en función de si se involucran activamente en las asociaciones empresariales o no, cuanto más involucrados mayor grado de adhesión, y de si se dedican exclusivamente al turismo o no. En este último caso impera el sentimiento general de decepción al no ver resultados inmediatos.

La segunda conclusión se refiere a la estructura de las relaciones desplegadas para la gestión pública del turismo. Las relaciones en este territorio de alta densidad poblacional están menos presentes de lo que desde la tradicional sociología estructural cabría pensar: no basta con un elevado número de habitantes para que exista una red densa de relaciones. Esto contribuye al dilema que se le plantea al Estado contemporáneo en materia de gobernanza, pues necesita crear redes para propiciar los proyectos colectivos, pero a la vez ve sus propios programas obstruidos por estas mismas redes (Moscardo, 2013). La razón de este hecho tiene que ver con la paradójica cercanía a la capital. El territorio comarcal ya ha sido tildado en otras investigaciones de "no cohesionado" por el desmantelamiento del sector agrario y, sobre todo, la dinámica de borde metropolitano: la región urbana de Madrid reafirma la debilidad de los vínculos intermunicipales, así como el peso de las áreas centrales en la organización socioeconómica de la comarca (Abad Aragón, 2014). La gestión del turismo como materia de acción pública no rompe esta lógica.

Las posibilidades de que prospere un destino de base comarcal en este caso de estudio se revelan difíciles al enfrentarse a la débil cohesión de sus vínculos internos, a los perímetros cambiantes de las políticas públicas (y por tanto perímetros de financiación), a la polarización de las relaciones por la Comunidad de Madrid y al peso de la actividad agroindustrial en la comarca. Para desenclavar esta red de gestión pública del desarrollo turístico se hace pertinente trascender los perímetros de actuación de las políticas públicas para conectar los principales nodos de atracción, como Aranjuez y Chinchón, con el entorno teniendo en cuenta que, los viajes en la Comunidad de Madrid se estructuran a partir de desplazamientos de día o fines de semana.

Como propuesta práctica, se hace necesario concebir las periferias rurales metropolitanas como áreas específicas dentro de la PEDR. Este tipo de espacios ha sido históricamente olvidado por la PEDR que, al aplicar los mismos criterios que para territorios rurales remotos, ha provocado aquí la creación de territorios rurales "ex nihilo", inventados, en vez de contemplar sus especificidades, como la escala regional a la que deben leerse (Errington, 1994). Los GAL de la Comunidad de Madrid demuestran haber utilizado el proyecto de cooperación "Madrid Destino Rural" para superar esta situación y ya han iniciado los procedimientos para contemplar la financiación de actuaciones de promoción "fuera" de los territorios LEADER, en la propia ciudad de Madrid para ganar visibilidad. Se requiere un nuevo marco de actuación de la PEDR en estas áreas específicas y cuyos límites sean menos cambiante, también a escala europea. 


\section{BIBLIOGRAFÍA}

ABAD ARAGÓN, L.D. (2014): «Gobernanza en espacios periurbanos a través de la iniciativa europea LEADER. El caso de la Comarca madrileña de Las Vegas», Anales de Geografía de La Universidad Complutense, vol. 34 (1), pp. 9-32.

BAGGIO, R., SCOTT, N. y COOPER, C. (2010): Network science: A Review Focused on Tourism», Annals of Tourism Research, vol. 37 (3), pp. 802-827.

BARBINI, F.M. y PRESUTTI, M. (2014): «Transforming a peripheral area in an emerging tourism destination», Tourism Geographies, vol. 16 (2), pp. 190-206.

BARRADO TIMÓN, D. (1999a): Actividades de ocio y recreativas en el medio natural de la Comunidad de Madrid. La ciudad a la búsqueda de la naturaleza. Madrid, Comunidad de Madrid, Consejería de Medio Ambiente.

BARRADO TIMÓN, D. (1999b): «El proyecto del parque temático de San Martín de la Vega en el contexto de periurbanización de los equipamientos de ocio en Madrid», Boletín de La A.G.E., $\mathrm{n}^{\circ}$ 28, pp. 133-143.

BERITELLI, P. (2011): «Cooperation among prominent actors in a tourist destination». Annals of Tourism Research, vol. 18 (4), pp. 639-652.

BIDDULPH, R. (2015): «Limits to mass tourism's effects in rural peripheries», Annals of Tourism Research, ${ }^{\circ}$ 50, pp. 98-112.

BOCK, B.B. (2016): «Rural Marginalisation and the Role of Social Innovation; A Turn Towards Nexogenous Development and Rural Reconnection», Sociologia Ruralis, vol. 56 (4), pp. 552-573.

BOTE GÓMEZ, V. (1995): «La estrategia del turismo metropolitano: el caso de Madrid», Estudios Turísticos, $\mathrm{n}^{\circ}$ 126, pp. 101-118.

BOUBA-OLGA, O., CARRINCAZEAUX, C. y CORIS, M. (2008): «La proximité, 15 ans déjà ! Avant-propos». Revue d'Économie Régionale y Urbaine, $\mathrm{n}^{\circ}$ 3, pp. 1-9.

BRAMWELL, B. y LANE, B. (2000): Tourism collaboration and partnerships e Politics, practice and sustainability. Sydney, Channel View Publications.

BUCIEGA ARÉVALO, A. y ESPARCIA PÉREZ, J. (2018): «Desarrollo, territorio y capital social. Un análisis a partir de dinámicas relacionales en el desarrollo rural», Redes. Revista Hispana Para El Análisis de Redes Sociales, vol. 24 (1), pp. 81-113.

CALLE VAQUERO, M. DE LA. (2018): «El patrimonio cultural en los pequeños municipios: salvaguarda y aprovechamiento sostenible», Revista Democracia y Gobierno Local, $\mathrm{n}^{\circ} 42-43$, pp. 513.

CALLE VAQUERO, M. DE LA, FERREIRO CALZADA, E. y MENDOZA DE MIGUEL, S. (2018): «Concentración y desconcentración de la actividad turística sobre el espacio urbano. Reflexiones en torno a Madrid», Polígonos. Revista de Geografía, nº 30, pp. 143-170.

CALLE VAQUERO, M. DE LA, GARCÍA HERNÁNDEZ, M. y MÍNGUEZ GARCÍA, C. (2015): «El despliegue del ocio turistico en el territorio de la Comunidad de Madrid», Ciudad y Territorio, $\mathrm{n}^{\circ}$ 184, pp. 293-309.

CÀNOVES, G., GARAY, L. y DURO, J.A. (2012): «Turismo rural en España: Avances y retrocesos en los últimos veinte años», Papers de Turisme, n $^{\circ}$ 51, pp. 7-21. 
CARSON, D.A., CARSON, D.B. y HODGE, H. (2014): «Understanding local innovation systems in peripheral tourism destinations», Tourism Geographies, vol. 16 (3), pp. 457-473.

CANTO FRESNO, C. DEL (1994). «La periferia metropolitana de Madrid como espacio de ocio: una nueva ruralidad». Economía y Sociedad, no 11, pp. 131-147.

CHAPERON, S. y BRAMWELL, B. (2013). «Dependency and agency in peripheral tourism development», Annals of Tourism Research, vol. 40 (1), pp. 132-154.

CHEVALIER, P. (2014): Action locale et développement rural en Europe : le modèle européen LEADER 2007. New York, Peter-Lang.

COMUNICACIÓN Y CONSULTORÍA TURÍSTICA. (2001): Diagnóstico turístico de Chinchón. Análisis del mercado: demanda.

COMUNIDAD DE MADRID. (2016): Estrategia de Turismo de la Comunidad de Madrid (2016-2019).

CONDEVAUX, A., GERALDINE, D.-T. y GRAVARI-BARBAS, M. (2016): «Avant et après le(s) tourismes(s). Trajectoires des lieux et rôles des acteurs du tourisme « hors des sentiers battus ». Une analyse bibliographique», Via Tourism Review, ${ }^{\circ} 9$.

DÍAZ SORIA, I. y LLURDÉS COIT, J.C. (2013): «Reflexiones sobre el turismo de proximidad como una estrategia para el desarrollo local», Cuadernos de Turismo, $\mathrm{n}^{\circ}$ 32 , pp. 65-88.

DREDGE, D. (2006): «Policy networks and the local organisation of tourism», Tourism Management, vol. 27 (2), pp. 269-280.

EHRLICH, K. (2017): "New Rural Tourism Paradigm in Submetropolitan Areas", en Sznajder, M.J. (Ed.), Metropolitan Commuter Belt Tourism. London, Routledge.

ERRINGTON, A. (1994): «The peri-urban fringe: Europe's forgotten rural areas», Journal of Rural Studies, vol. 10 (4), pp. 367-375.

ESCUDERO, L.A. (2006): «Nuevos espacios de ocio urbano, los centros comerciales: un ejemplo: Madrid-Xanadú", en Lacosta Aragües, A.J. (Ed.), Turismo y cambio territorial: ¿eclosión, aceleración, desbordamiento? IX Coloquio de Geografía del Turismo, Ocio y Recreación. Zaragoza, Prensas Universitarias de Zaragoza, pp. 107-118.

FONSECA, F.P. y RAMOS, R.A R. (2012): «Heritage Tourism in Peripheral Areas : Development Strategies and Constraints». Tourism Geographies, vol. 14 (3), pp. $467-$ 493.

FULLERTON, B. y BROUDER, C. (n.d.): «Rural tourism in a metropolitan hinterland: co-evolving towrads a resilient urban-fringe», en Koster, R y Carson, D. (Eds.) Perspectives on Rural Tourism Geographies: Case Studies from Developed Nations and the Exotic, the Fringe and the Boring Bits in Between. Dodregt, Springer International Publishing.

GARCÍA HERNÁNDEZ, M. y CALLE VAQUERO, M. DE LA. (2010): «Reflexiones sobre el turismo cultural. La aportación de la cultura en la conformación de flujos turísticos emisores en España y la Comunidad de Madrid». Anales de Geografía de La Universidad Complutense, vol. 30 (2), pp. 31-58.

GRAZULEVICIUTE-VILENISKE, I. y VITKUVIENE, J. (2012): «Towards integration of rural heritage in rurban landscape. Case of Lithuanian Manor Residencies», American Journal of Tourism Management, vol. 1 (2), pp. 53-63. 
HALKIER, H., MÜLLER, D. K., GONCHAROVA, N. A., KIRIYANOVA, L., KOLUPANOVA, I. A., YUMATOV, K.V. y YAKIMOVA, N. S. (2019). «Destination development in Western Siberia: tourism governance and evolutionary economic geography». Tourism Geographies, vol. 21 (2), pp. 261-283.

HALL, C.M., HARRISON, D., WEAVER, D. y WALL, G. (2013): «Vanishing Peripheries: Does Tourism Consume Places?", Tourism Recreation Research», vol. 38 (1), pp. 71-92.

HILLS, T.L. y LUNDGREN, J. (1977): «The impact of tourism in the Caribbean: a methodological study», Annals of Tourism Research, vol. 4 (5), pp. 248-267.

IOANNIDES, D. y PETERSEN, T. (2013): «Tourism “non-entrepreneurship" in peripheral destinations: A case sudy of small and medium tourism enterprises on Bornholm. Denmark", Tourism Geographies, vol. 5 (4), pp. 408-435.

JAARSMA, R.F. y VRIES, J.R. DE. (2013): «Former Farm Buildings Reused as Rural Villa, Building Contractor or Garden Centre: Consequences for Traffic Flows on Minor Rural Roads in a Changing Countryside», European Countryside, vol. 5 (1), pp. 38-51.

JAMAL, T. y GETZ, D. (1995): «Collaboration theory and community tourism planning», Annals of Tourism Research, vol. 22 (1), pp. 186-204.

KAUPPILA, P., SAARINEN, J. y LEINONEN, R. (2009): «Sustainable Tourism Planning and Regional Development in Peripheries: A Nordic View», Scandinavian Journal of Hospitality and Tourism, vol. 9 (4), pp. 424-435.

LACQUEMENT, G. y RAYNAL, J. (2013): «Acteurs et ressources du développement local en Allemagne orientale : le territoire rural au prisme des projets du programme européen LEADER European programme LEADER projects», Annales de Geographie, $\mathrm{n}^{\circ} 4$ (692), pp. 393-421.

LANE, B. y KASTENHOLZ, E. (2015): «Rural tourism: the evolution of practice and research approaches - towards a new generation concept?», Journal of Sustainable Tourism, vol. 23, (8-9), pp. 1.133-1.156.

LAZEGA, E. (2007): Les réseaux sociaux e structures relationnelles. Paris, PUF. Coll. Que sais-je?

MANSILLA, J.A. y MILANO, C. (2019): «Becoming centre: tourism placemaking and space production in two neighborhoods in Barcelona», Tourism Geographies.

MARKUSEN, A. (2003): «Fuzzy concepts, scanty evidence, policy distance: the case for rigour and policy relevance in critical regional studies», Regional Studies, vol. 37 (6-7), pp. 701-717.

MARTÍN GIL, F. y MARTÍN HERNANZ, I. (2008): «Problemas de sostenibilidad turística en destinos rurales maduros: el ejemplo de Patones», en Troitiño Vinuesa, M.A., García Marchante, J-S- y García Hernández, M. (Eds.) Destinos turísticos: viejos problemas, ¿nuevas soluciones?. Cuenca, Universidad de Castilla-la-Mancha, pp. 503-514.

MARTÍN HERNANZ, I. y MARTÍN GIL, F. (2017): «Interpretación del patrimonio y gestión sostenible del turismo en espacios rurales. Los casos de Montejo de la Sierra y Patones», Boletín de La Asociación de Geógrafos Españoles, nº 72, pp. 169-194.

MERCKLE, P. (2011): Les réseaux sociaux. París, Ed. La Découverte. 
MERINERO RODRÍGUEZ, R. (2015): «La agenda de investigación del turismo mediante el Análisis Cuantitativo de Redes Sociales (QSNA)», Cuadernos de Turismo, $\mathrm{n}^{\circ} 36$, pp. 269-294.

MICHAEL HALL, C. (2011): «A typology of governance and its implications for tourism policy analysis», Journal of Sustainable Tourism, vol. 19 (4-5), pp. 437-457.

MÍNGUEZ GARCÍA, C. (2007): «Planificación y gestión turística en destinos patrimoniales: el caso del Real Sitio de San Lorenzo de El Escorial (Comunidad de Madrid)», Anales de Geografía de La Universidad Complutense, vol. 27 (1), pp. 83-102.

MOSCARDO, G. (2013): «Exploring social representations of tourism planning: issues for governance», en Bramwell, B y Lane, B. (Eds.) Tourism Governance: critical perspectives on tourism and governance. New York, Taylor y Francis.

MÜLLER, D.K. y JANSSON, B. (2007): Tourism Peripheries. Perspectives from the Far North and South. Oxfordshire, CAB International.

NOGUEIRA, S. y PINHO, J.C. (2015): «Stakeholder Network Integrated Analysis: The Specific Case of Rural Tourism in the Portuguese Peneda-Gerês National Park», International Journal of Tourism Research, vol. 17 (4), pp. 325-336.

PÉREZ, J.A. (2013, JANUARY 21): "Chinchón, un pueblo volcado en el turismo”. ABC. Disponible en www.abc.es/local-madrid/20130121/abci-chinchon-pueblo-volcadoturismo-201301201815.html

POTTER, R.B. (2001): «Geography and development: core and periphery?», Area, $\mathrm{n}^{\circ} 33$, pp. 422-427.

RÁTZ, T., SMITH, M. y MICHALKÓ, G. (2008): «New Places in Old Spaces: Mapping Tourism and Regeneration in Budapest», Tourism Geographies, vol. 10, pp. 429-451.

RED2RED CONSULTORES. (2015): Balance de la actividad de la Asociación de Desarrollo Rural Aranjuez-Comarca de las Vegas durante el periodo 2007-2013.

ROMEIRO, P. y COSTA, C. (2010): «The potential of management networks in the innovation and competitiveness of rural tourism: A case study on the Valle del Jerte (Spain)», Current Issues in Tourism, vol. 13 (1), pp. 75-91.

SALVATORE, R., CHIODO, E. y FANTINI, A. (2018): «Tourism transition in peripheral rural areas: Theories, issues and strategies», Annals of Tourism Research, vol. 68, pp. 41-51.

SCOTT, M. (2004): «Building institutional capacity in rural Northern Ireland: The role of partnership governance in the LEADER II programme», Journal of Rural Studies, vol. 20 (1), pp. 49-59.

SCOTT, N. y BAGGIO, R. (2008): «Four Australian Cases», Annals of Tourism Research, vol. 35 (1), pp. 169-188.

SCOTT, N., BAGGIO, R. y COOPER, C. (2008): Network Analysis and Tourism, From Theory to Practice. Toronto, Channel View Publications.

SIMON, G. (2018): «Paris-Plages or the staging of distance: tourist referents in the 'everyday' world», Current Issues in Tourism, vol. 23 (2), pp. 153-163.

SOLÍS, E., UREÑA, J.M. y MOHÍNO, I. (2018): «Centralidad territorial y especialización funcional como guía para la intervención en municipios con conjunto histórico. El caso de la región urbana madrileña», ACE: Architecture, City and Environment = Arquitectura, Ciudad y Entorno, vol. 13 (37), pp. 99-132. 
STRZELECKA, M., BOLEY, B.B. y WOOSNAM, K.M. (2017): «Place attachment and empowerment: Do residents need to be attached to be empowered?», Annals of Tourism Research, vol. 66, pp. 61-73.

TROITIÑO TORRALBA, L. (2011): «Las ciudades patrimonio de la humanidad de la región turística de Madrid: niveles medios de funcionalidad y adecuación turística del patrimonio cultural», Papers de Turisme, nº 6, pp. 109-131.

TROITIÑO VINUESA, M.Á., GARCÍA HERNÁNDEZ, M. y CALLE VAQUERO, M. DE LA. (2011): «Las actividades turístico-recreativas en los Planes de Gestión de los Sitios Patrimonio Mundial. El caso de Aranjuez, Paisaje Cultural de la Humanidad», Cuadernos de Turismo, $\mathrm{n}^{\circ} 27$, pp. 907-929.

TROITIÑO VINUESA, M.Á. y TROITIÑO TORRALBA, L. (2018): «Visión territorial del patrimonio y sostenibilidad del turismo», Boletín de La Asociación de Geógrafos Españoles, $\mathrm{n}^{\circ} 78$, pp. 212-224.

TURNER, L. y ASH, J. (1975): The Golden Hordes: International Tourism and the Pleasure Periphery. London, Constable.

VAN DER ZEE, E. y VANNESTE, D. (2015): «Tourism networks unravelled; a review of the literature on networks in tourism management studies», Tourism Management Perspectives, vol. 15, pp. 46-56.

VELASCO GONZALEZ, M. (2016): «Entre el poder y la racionalidad: gobierno del turismo, política turística, planificación turística y gestión pública del turismo», PASOS. Revista de Turismo y Patrimonio Cultural, vol. 14 (3), pp. 577-594.

VUIN, A., CARSON, D.A., CARSON, D. B. y GARRETT, J. (2016): «The role of heritage tourism in attracting "active" in-migrants to "low amenity" rural areas», Rural Society, vol. 25 (2), pp. 134-153.

WEAVER, D. (1988): «The evolution of a "plantation"tourism landscape on the Caribbean Island of Antigua», Tijdschrift Voor Economische En Sociale Geografie, vol. 79, pp. 319-331.

WEAVER, D. (1998): «Peripheries of the periphery», Annals of Tourism Research, vol. 25 (2), pp. 292-313.

WEAVER, D. (2016): «Center-Periphery», en Jafari, J. y Xiao, H. (Eds.) Encyclopedia of Tourism. Switzerland, Springer International Publishing.

YUBERO, C. y CHEVALIER, P. (2018): «The Illusion of Proximity in Territorial Construction. An Approach to Tourism Development Via Social Networks in Sierra De Albarracín (Spain)», European Countryside, vol. 10 (3), pp. 442-461.

YUBERO, C. y GARCÍA HERNÁNDEZ, M. (2016): «Turismo en Albarracín y Comarca. Acción pública local y dinámica reciente en clave de desarrollo turístico sostenible», Anales de Geografia de La Universidad Complutense, vol. 36 (1), pp. 173-194.

ZASADA, I. y PIORR, A. (2015): «The Role of Local Framework Conditions for the Adoption of Rural Development Policy: An Example of Diversification, Tourism Development and Village Renewal in Brandenburg, Germany», Ecological Indicators, vol. 59, pp. 82-93. 
